\title{
CUSTOM BEAM SHAPING \\ FOR HIGH-POWER FIBER LASER WELDING
}

\section{THESIS}

\author{
Presented in Partial Fulfillment of the Requirements for \\ the Degree Master of Science in the \\ Graduate School of The Ohio State University
}

By

Brian M. Victor, B.S.

The Ohio State University

2009

Dissertation Committee:

Professor Charles Albright, Advisor

Professor Dave Farson

Approved by

Advisor

Welding Engineering

Graduate Program 


\begin{abstract}
With the ever increasing power and performance of solid-state lasers, autogenous laser welding is becoming more practical for thick-section welding applications. High-power, high-beam-quality fiber lasers can produce high aspect ratio (depth/width) welds at productive travel speeds with minimal distortion. However, autogenous laser welding can produce undercutting or other geometric stress concentrations at the weld toes.

Through the design of custom optics, a laser beam can be directed to produce custom power distributions at the work, which can allow the fusion profile of a weld to be optimized for particular applications. By deflecting a portion of the laser power to trail the weld pool, the weld toes can be remelted to smooth stress concentrators and improve fatigue performance. This paper discusses the design and testing of a custom multi-spectral zinc sulfide beam shaping optic with a 10-kW IPG fiber laser.

In this research, laser welding parameters were developed for single-pass conventional welding. Feasibility trials were then conducted to prove the concept of smoothing the weld toes. To simulate the concept of a custom three-spot optic, three passes of a conventional optic were tested. Finally, a custom optic was designed and tested to evaluate welding and smoothing the weld toes with a
\end{abstract}


single-pass solution. Weld toe angles in stainless steel were improved from 125

to 163 degrees by welding with the custom optic instead of conventional optics. 


\section{ACKNOWLEDGEMENTS}

The following work was completed for and funded by the Edison Welding Institute $(\mathrm{EWI})$ in Columbus, Ohio. I wish to express my appreciation to the technical staff of EWI including Stan Ream, Michael Fallara, and Greg Firestone for their assistance in completing the design, testing, and analysis of this work.

I would like to thank Dr. Craig Walters of Craig Walters Associates in

Dublin, Ohio for his help in the design and modeling of the custom beam shaping optic. I am also thankful for the informal education on optic design Dr. Walters provided during this research.

I am grateful to Dr. Charles Albright, my academic advisor, for his guidance and support in this research as well as for his patience throughout the progression of my graduate degree.

This research was supported by a contribution of the State of Ohio, Department of Development, and Thomas Edison Program, which provided funding in support of Edison Technology and Industry Center Services. 
VITA

February $12,1983 \ldots \ldots \ldots \ldots \ldots \ldots \ldots$

The Ohio State University
Edison Welding Institute (EWI)
Columbus, Ohio

\section{FIELDS OF STUDY}

Major Field: Welding Engineering 


\section{TABLE OF CONTENTS}

Page

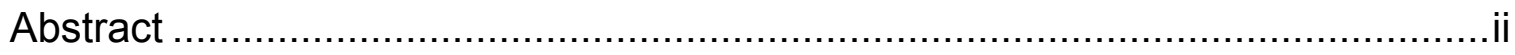

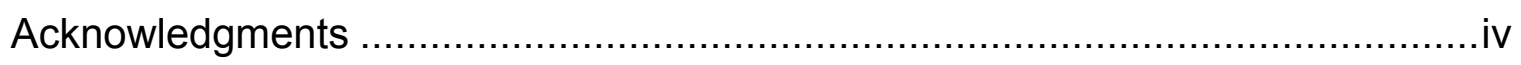

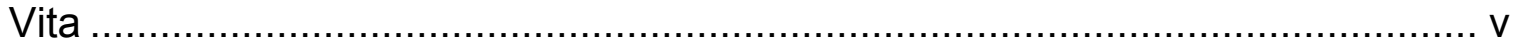

List of Tables ……................................................................................ vii

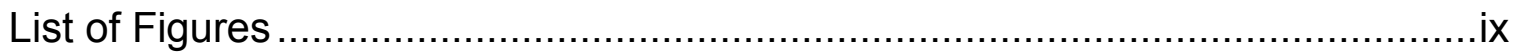

Chapters:

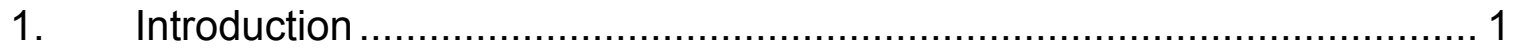

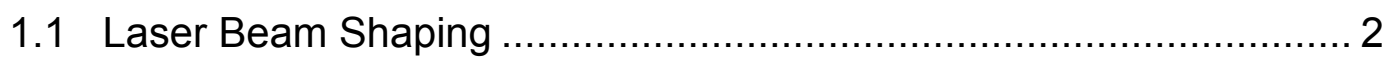

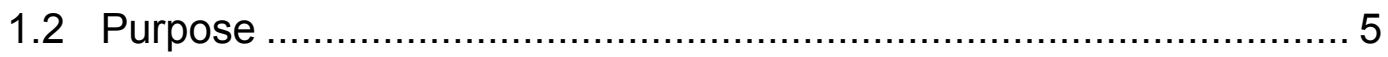

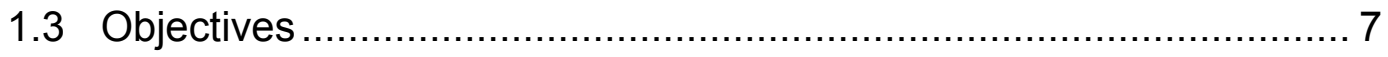

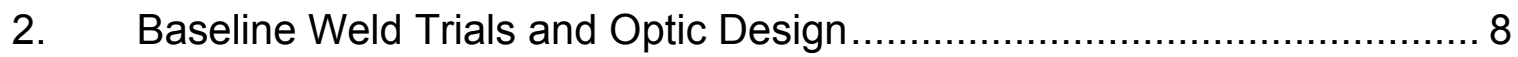

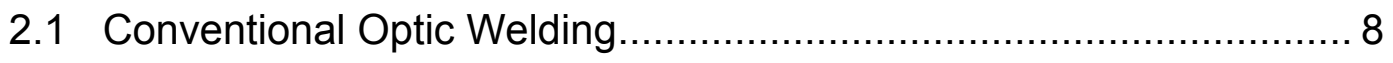

2.1.1 Keyhole Welding with Conventional Optics ......................... 9

2.1.2 Conduction Smoothing with Conventional Optics …............. 10

2.1.3 Characterization of Welding and Smoothing Beams ............ 13

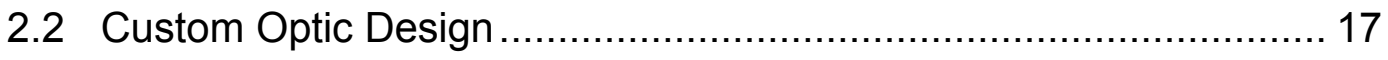


3. Custom Optic Testing and Welding ……….................................... 24

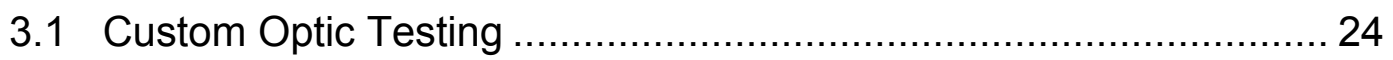

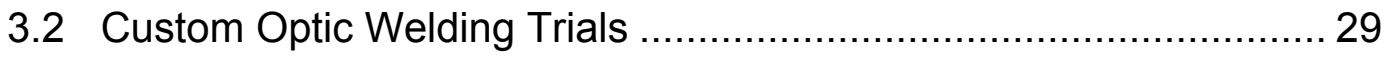

4. Conclusions and Future Work .......................................................... 35

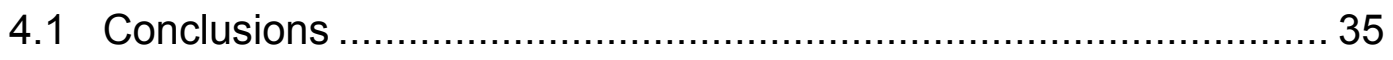

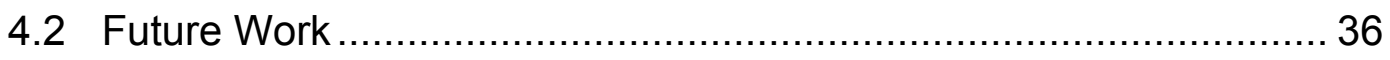

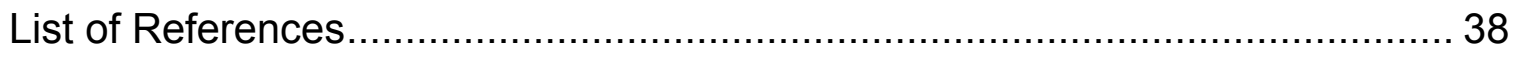

Appendix A PRIMES Beam Diagnostic Measurements ................................... 40

Appendix B Laser Power Measurements ………................................... 45 


\section{LIST OF TABLES}

Table $\quad$ Page

2.1 Variables Investigated for Keyhole Welding with Conventional Optics ...... 9

2.2 Baseline Parameters for Keyhole Welding with Conventional Optics ........ 9

2.3 Parameters for Conduction Smoothing with Conventional Optics........... 12

2.4 PRIMES Beam Measurement Data .................................................. 15

2.5 Design Parameters for Each Beam of the Custom Optic ....................... 17

3.1 Variables Investigated for Welding with Custom Three-Spot Optic.......... 29

3.2 Welding Parameters for Custom Three-Spot Optic............................... 30

3.3 Comparison of Weld Toe Angle Measurements …............................... 33

B.1 Power Measurements of Conventional Optics and Custom Optics......... 46 


\section{LIST OF FIGURES}

Figure $\quad$ Page

2.1 Baseline Keyhole Weld Produced with Conventional Optics .................. 10

2.2 Conduction Smoothing Welds Produced with Conventional Optics ......... 12

2.3 Before and After Weld Toe Smoothing with Conventional Optics ........... 13

2.4 PRIMES Measurement Results for the Main Beam ............................... 14

2.5 PRIMES Measurement Results for the Smoothing Beam..................... 15

2.6 Illustration of EWI "Conventional" 10-kW Welding Optics ....................... 18

2.7 Drawing of Custom Optic Final Design by Craig Walters Associates ...... 19

2.8 Predicted Power Distribution of the Custom Optic Final Design by Craig

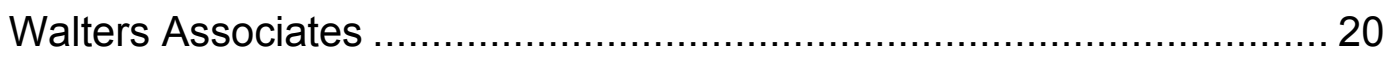

2.9 Ray Trace Generated in ZEMAX ${ }^{\mathrm{TM}}$ by Craig Walters Associates ............ 21

2.10 Solid Model of Custom Three-Spot Optic by Craig Walters Associates ... 21

2.11 Photo of the Finished Custom Three-Spot Optic Manufactured by II-VI,

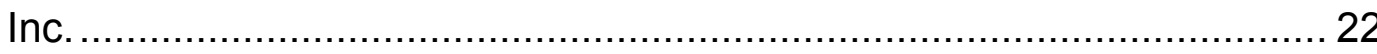

2.12 Interferometer Measurement of Flat Surface of Custom Optic Reported by

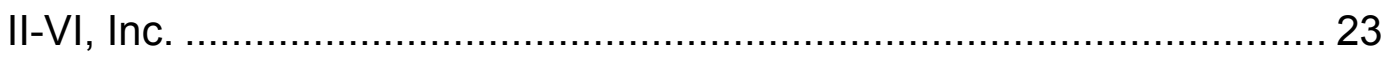

3.1 Illustration of Custom Optic Alignment Mechanism ............................... 25

3.2 Photo of the Installed Optic Alignment System …............................... 26

3.3 Photo of Burn Shot on Black Polyethylene from Custom Optic............... 27

3.4 Plastic Burn Shots for Alignment of Each Axis................................... 28 
3.5 Comparison of Custom Optic Weld Cross Section to Conventional Optic

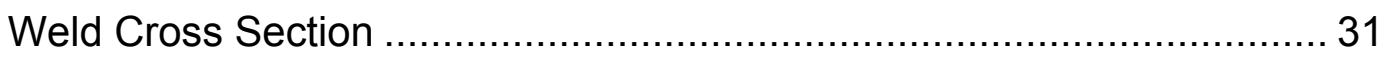

3.6 Photo of Weld End Craters Produced with the Custom Optic ................. 32

3.7 Cross Section of Custom Optic Weld ................................................. 32

A.1 Caustic Focus Measurement of Main Welding Beam from Conventional

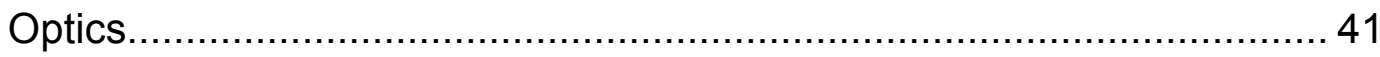

A.2 Single Plane Measurement of Main Welding Beam from Conventional

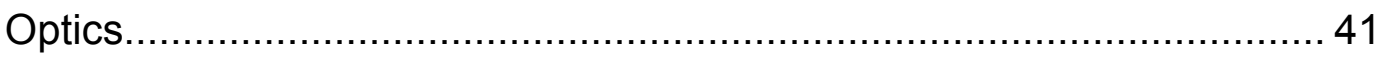

A.3 Measurement 1 of Out-of-Focus Smoothing Beam from Conventional

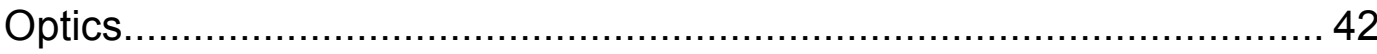

A.4 Measurement 2 of Out-of-Focus Smoothing Beam from Conventional

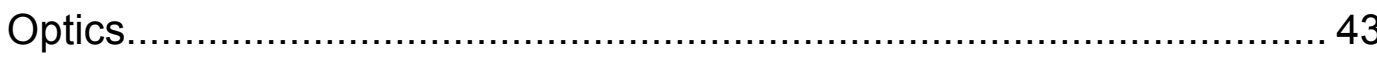

A.5 Measurement 3 of Out-of-Focus Smoothing Beam from Conventional Optics. 44 


\section{CHAPTER 1}

\section{INTRODUCTION}

A laser is a device that produces a concentrated coherent monochromatic beam of light [1]. Because laser beams are coherent and monochromatic, they can be transported over relatively large distances before being concentrated through the use of transmissive or reflective focusing optics [1]. Depending on the power density, or irradiance, of the focused beam at the work, a variety of material processing tasks can be achieved including welding, cutting, drilling, and heat treating. When welding with a laser beam, there are two general modes: penetration welding and conduction welding.

At high power densities all materials will evaporate if the beam energy can be absorbed [2]. When welding with high power densities, a cavity is usually formed in the material by this vaporization. This cavity, or keyhole, is then traversed through the material while the molten walls seal up behind it [2]. The result is what is known as a keyhole weld [2]. Penetration or keyhole welding can produce deep penetration welds with high aspect ratios at fast travel speeds.

Conduction-limited welding occurs when the power density is insufficient to cause vaporization and generate a keyhole at a given welding speed [2]. The laser beam is absorbed at the surface of the material and the energy travels into 
the workpiece by thermal conduction [3]. Once a melt pool is established, convection within the liquid metal drives an increase in penetration. This relatively slow process limits the depth that can be melted and hence limits the weld penetration [3]. Both conduction and keyhole welding were investigated in this research.

\subsection{Laser Beam Shaping}

Beam shaping is the process of altering an input beam to produce an output beam with a desired spatial or irradiance profile. In addition to welding and materials processing, laser beam shaping can be used for applications such as illumination, holography, lithography, printing, weaponry, and optical data/image processing $[4,5]$. For each of these uses, the application needs for power density and spatial profile are different. There are many beam shaping methods, both reflective and refractive, to accommodate these different needs; however, most laser beam shaping techniques can be divided into three broad classes [5].

The first, and most simple, class of beam shaping is aperturing [5], or selecting a useful portion of the input beam. This is achieved by using an aperture to allow some portion of the beam power to pass through while the rest of the beam is either reflected or absorbed. For example, a Gaussian-like beam could be masked by an aperture to allow only the central portion of the beam to pass through [5]. The drawback to this technique is that there can be considerable power loss and the unused beam energy must be managed. 
The second class of beam shaping is known as field mapping $[4,5]$. A field mapper transforms an input beam into a desired output beam in a controlled manner and can be effectively lossless [4]. This technique could be used to transform a single-mode Gaussian beam into a beam with uniform irradiance [5]. Field mapping is applicable to well-defined, single-mode laser beams.

The third class of laser beam shaping is homogenizing or integrating the beam. In this technique, the input beam can be broken up by an array of lenses or facets. The multiple beams are then focused to an output plane by a primary optic where they overlap to produce the desired image. The array of facets or lenslets can be separate from the primary optic or they could be incorporated into the surface of the primary optic. This optical configuration is known as a beam integrator.

The term integrator comes from the fact that the output beam pattern is a sum of the diffraction patterns determined by the lenslet or facet array [5]. Beam integrators can be reflective or refractive and can be designed to be effectively lossless. Beam integration can also be achieved with a homogenizer such as a kaleidoscope integrator. This involves a reflective rectangular cavity where different parts of the input beam undergo different reflection paths so that the output beam is roughly a randomized sum [6]. Beam integrators or homogenizers work well for multimode beams where the input profile may not be well characterized.

Depending on the materials processing application, different beam shaping methods may be used. Previous researchers have used custom optic 
configurations of different beam shaping methods to tailor the characteristics of the resulting weld.

Killpatrick has suggested the use of custom power distributions to weld dissimilar materials. Each material would be welded with a split beam. Each section of the beam has a different irradiance to produce the desired melt volume in each material. He also suggests using a custom beam shape to control the heat affected zone and permit stress relief as the fusion zone cools [7].

Liu and Kannatey-Asibu used an elliptical beam for preheat followed by a line source for welding. The elliptical beam was also used for post-heating the weld [8]. Other applications have used custom beam shapes such as rectangles, stripes, and lines for heat treating. In a separate study, Liu and Kannatey-Asibu used a dual beam (twin spot) configuration to weld with one spot and preheat or post-heat with the other [9]. Russ et. al. welded aluminum with a double focus (twin spot) technique to reduce porosity and spatter [10].

Kell et. al. used diffractive optical elements to change power distribution and therefore adjust the shape of weld penetration profiles [11]. Hammond et. al. also used diffractive optical elements to produce a custom power distribution for joining dissimilar materials including combinations of aluminum, Inconel, and stainless steel [12].

With the hybrid laser gas metal arc welding process, Cho, Choi, and Farson have used a defocused laser spot to promote a wider weld pool than conventional gas metal arc welding (GMAW) [13]. This defocused laser beam was positioned alongside the GMAW weld to promote spreading of the weld pool 
and to improve the weld toe angle increasing fatigue life. Cho, Choi, and Farson have also simulated and proven the suppression of weld bead humping formation in GMAW welds by adding additional heat input from a defocused laser beam $[14,15]$

Others have used oblong spots, twin spots, or other custom shapes to reduce weld pool humping at high speeds, decrease porosity, reduce defects from coated materials, alter the penetration profile, or improve weld quality [16, 17, 18]. However, little has been found involving the use of custom optics to produce a deep penetration keyhole weld and then smooth the weld surface in a single pass.

\subsection{Purpose}

High-power, high-beam-quality, solid-state lasers are rapidly emerging as a significant advancement in laser processing. Fiber lasers have led the advancement of high-brightness, solid-state lasers. With an increase in laser power and performance, a decrease in cost per Watt, and beam delivery via optical fibers, the laser welding process is finding many new uses in deep penetration applications.

A wide range of industries can benefit from the deep penetration, narrow weld width, and low heat input possible with fiber lasers. However, as higher power lasers push the limits of penetration and travel speeds, new welding concerns can arise. When laser welding at high travel speeds, discontinuities can occur at the weld toes. One possible discontinuity, undercutting, is due to a 
movement of molten material from the edges of the weld pool to the center. When the weld pool solidifies, the weld shows a longitudinal undercut along the length of each weld toe. Additionally, laser welds can exhibit sharp toe angles at the transition between the reinforcement of the weld and the surface of the base material. Without the addition of filler metal or a secondary heat source, these types of geometric notches can be common at the toes of autogenous laser welds.

In many of the new welding applications being addressed by high-power fiber lasers, fatigue performance of the welded joint is an important consideration. One measure for the success of weldments in fatigue-critical applications is the geometric profile of the welded joint. Reducing geometric stress concentrations in the weld profile can greatly improve the fatigue performance of a welded structure.

If a fatigue-critical joint is known to produce these types of discontinuities when laser welded, the joint can be designed with a factor of safety to allow for the geometric stress concentrators along the weld toes to be present in service. In some applications, the weld reinforcement and top surface of the base material can be machined off to eliminate any geometric surface inconsistencies in the welded region. In other cases, the surface of the weld can be rewelded with a second "cosmetic" pass to remelt the reinforcement and provide a smooth transition at the weld toes. 
Each of these solutions requires overdesigned joints or extra time involved in a secondary machining or welding procedure. The purpose of this research is to produce welds with decreased geometric stress concentrations.

\subsection{Objectives}

The goal of this research is to develop a custom optical solution for laser beam shaping that will both weld the joint and produce smooth weld toes in one pass. This will be accomplished by focusing the laser beam into three spots. The center spot will provide the main penetration of the weld while two low-power trailing spots will smooth the weld toes by remelting the surface of the weld.

This research focused on the follow objectives.

- Produce baseline welds with conventional optics to show typical fusion profile and weld toe geometry.

- Design a custom three-spot optic solution capable of welding and smoothing the weld toes in a single pass to reduce geometric stress concentrations.

- Produce welds with the custom three-spot optic and compare the resulting weld profiles to cross sections from baseline welds produced with conventional optics. 


\section{CHAPTER 2}

\section{BASELINE WELD TRIALS AND OPTIC DESIGN}

Welding trials with conventional single-spot optics and a 10-kW IPG Yb-

fiber laser were conducted. In these trials, baseline welds were produced to show a typical profile of a conventional laser weld. These baseline welds were later compared to welds produced with the custom beam shaping optic. To determine the power distribution needed to smooth the weld toes, conductionlimited welds were also produced using conventional optics. The conventionaloptic parameters for producing penetration and conduction welds would then help define the design of the custom beam shaping optic.

\subsection{Conventional Optic Welding}

Partial penetration welding trials were completed in the bead-on-plate configuration in the flat position. The material welded was 8-mm thick, type 304 stainless steel. Industrial grade argon was used as the shielding gas for all welding trials. All welding trials were completed at the High Power Laser Lab of Edison Welding Institute (EWI) [19].

Using conventional optics, keyhole welds were produced and evaluated. Then, by using a second and third pass of the laser, geometric discontinuities at 
each weld toe were remelted and smoothed. For these smoothing trials, the laser beam was moved up out of focus to increase the spot size and decrease the power density of the beam.

\subsubsection{Keyhole Welding with Conventional Optics}

Bead-on-plate welding trials were conducted to produce keyhole welds. Three travel speeds and three laser power levels were evaluated for one spot size. These variables are listed in Table 2.1. All welding was conducted with focus at the top surface of the plate. From these trials, one set of parameters, listed in Table 2.2, was selected as the baseline condition for future comparison. Figure 2.1 is a cross section taken from a weld produced with the baseline parameters. The penetration, fusion profile, and weld toe geometry of this baseline weld were documented for future comparison.

\begin{tabular}{|c|c|c|c|}
\hline $\begin{array}{c}\text { Travel Speed } \\
(\mathrm{ipm})\end{array}$ & $\begin{array}{c}\text { Laser Power } \\
(\mathrm{kW})\end{array}$ & $\begin{array}{c}\text { Calculated } \\
\text { Spot Size } \\
(\mu \mathrm{m})\end{array}$ & Focal Position \\
\hline 120 & 5 & \multirow{2}{*}{500} & Part surface \\
\hline 160 & 6 & & \\
\hline 200 & 7 & & \\
\hline
\end{tabular}

Table 2.1 - Variables Investigated for Keyhole Welding with Conventional Optics 


\begin{tabular}{|c|c|c|c|c|c|c|}
\hline $\begin{array}{c}\text { Travel } \\
\text { Speed } \\
(\mathrm{ipm})\end{array}$ & $\begin{array}{c}\text { Laser } \\
\text { Power } \\
(\mathrm{kW})\end{array}$ & $\begin{array}{c}\text { Fiber } \\
\text { Diameter } \\
(\mu \mathrm{m})\end{array}$ & $\begin{array}{c}\text { Collimation } \\
\text { Distance } \\
(\mathrm{mm})\end{array}$ & $\begin{array}{c}\text { Focusing } \\
\text { Distance } \\
(\mathrm{mm})\end{array}$ & $\begin{array}{c}\text { Calculated } \\
\text { Spot Size } \\
(\mu \mathrm{m})\end{array}$ & $\begin{array}{c}\text { Focal } \\
\text { Position }\end{array}$ \\
\hline 120 & 6 & 300 & 150 & 250 & 500 & $\begin{array}{c}\text { Part } \\
\text { surface }\end{array}$ \\
\hline
\end{tabular}

Table 2.2 - Baseline Parameters for Keyhole Welding with Conventional Optics

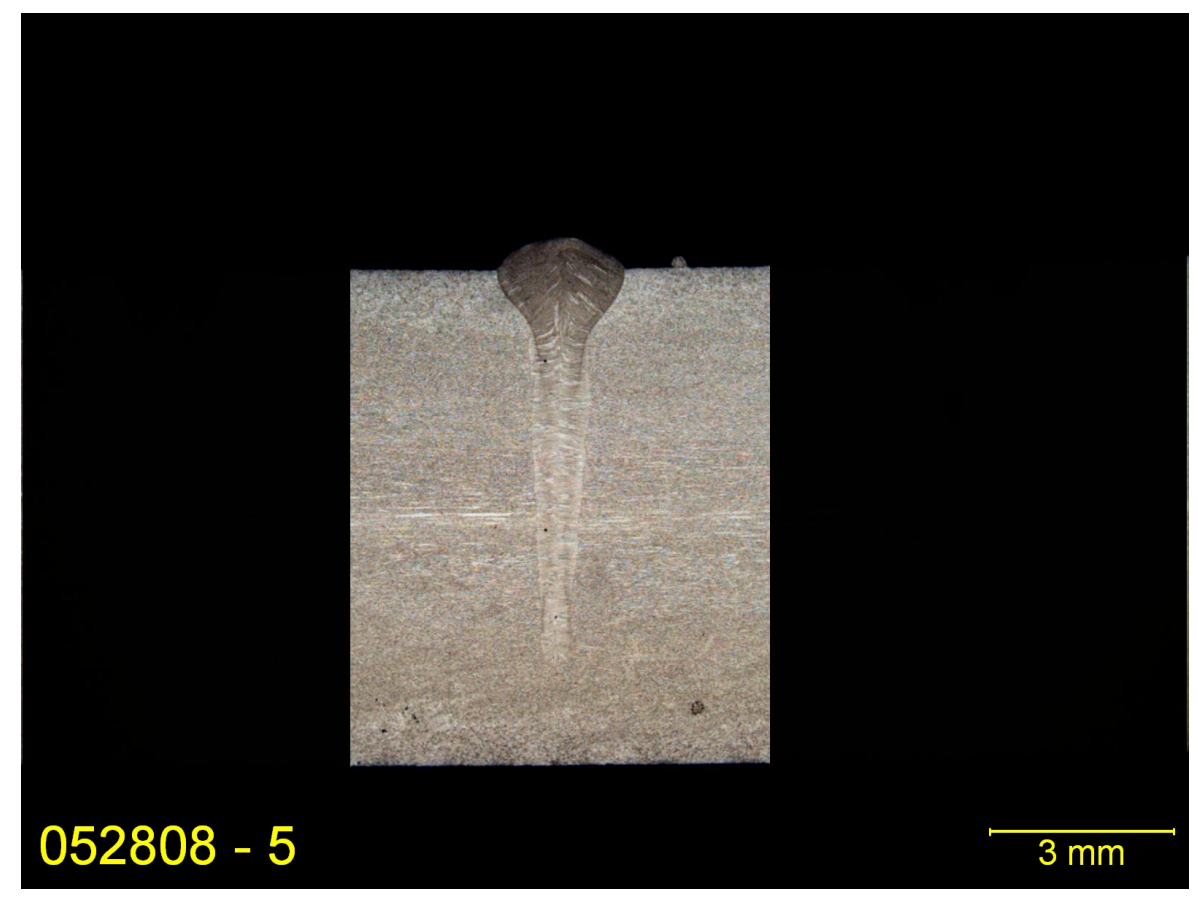

Figure 2.1 - Baseline Keyhole Weld Produced with Conventional Optics

\subsubsection{Conduction Smoothing with Conventional Optics}

To determine the relative power density and spot size necessary to smooth the weld toes, conduction-limited welding was evaluated. Initial trials consisted of remelting the weld toes of the previously-produced baseline keyhole 
welds. The laser power was reduced and the focal position was raised to produce an out-of-focus spot at the work. The beam was then traversed over the weld toe to remelt only the top surface. The reduced power and out-of-focus spot size produced a low power density on the work to make a conduction weld. The focal position, laser power, and lateral distance from the weld centerline were adjusted to develop optimum weld toe smoothing parameters.

In the final design of the custom optic, the total beam power would be divided into three beams. The main beam would produce the penetration and the other two beams would trail the first spot to remelt and smooth the weld toes. Because the penetration needed to be constant, the power of the main beam had to be the same as the baseline parameters $(6 \mathrm{~kW})$. Additional power would be needed to supply the two trailing beams with enough power to remelt the weld toes. Because the maximum power output of the fiber laser source was $10 \mathrm{~kW}$, the total power of all three beams needed to stay below $10 \mathrm{~kW}$. For this reason, the laser power was limited to less than $2 \mathrm{~kW}$ while developing the parameters for weld toe smoothing. Also, the three beams of the custom optic had to travel at the same speed. Therefore the travel speed was held constant at $120 \mathrm{ipm}$ during parameter development for weld toe smoothing.

In addition to visual examination of the weld surfaces, the welds were cross sectioned to determine the penetration depth and fusion profile. The optimum weld toe smoothing parameters are listed in Table 2.3. Figure 2.2 is a cross section showing the location and penetration of the toe-smoothing welds. Figure 2.3 shows the weld toe profile before and after the smoothing weld pass. 


\begin{tabular}{|c|c|c|c|c|c|c|}
\hline $\begin{array}{c}\text { Travel } \\
\text { Speed } \\
(\mathrm{ipm})\end{array}$ & $\begin{array}{c}\text { Laser } \\
\text { Power } \\
(\mathrm{kW})\end{array}$ & $\begin{array}{c}\text { Fiber } \\
\text { Diameter } \\
(\mu \mathrm{m})\end{array}$ & $\begin{array}{c}\text { Collimation } \\
\text { Distance } \\
(\mathrm{mm})\end{array}$ & $\begin{array}{c}\text { Focusing } \\
\text { Distance } \\
(\mathrm{mm})\end{array}$ & $\begin{array}{c}\text { Focal } \\
\text { Position } \\
(\mathrm{mm})\end{array}$ & $\begin{array}{c}\text { Distance } \\
\text { from } \\
\text { Centerline } \\
(\mathrm{mm})\end{array}$ \\
\hline 120 & 1.5 & 300 & 150 & 250 & +24 & 1.3 \\
\hline
\end{tabular}

Table 2.3 - Parameters for Conduction Smoothing with Conventional Optics

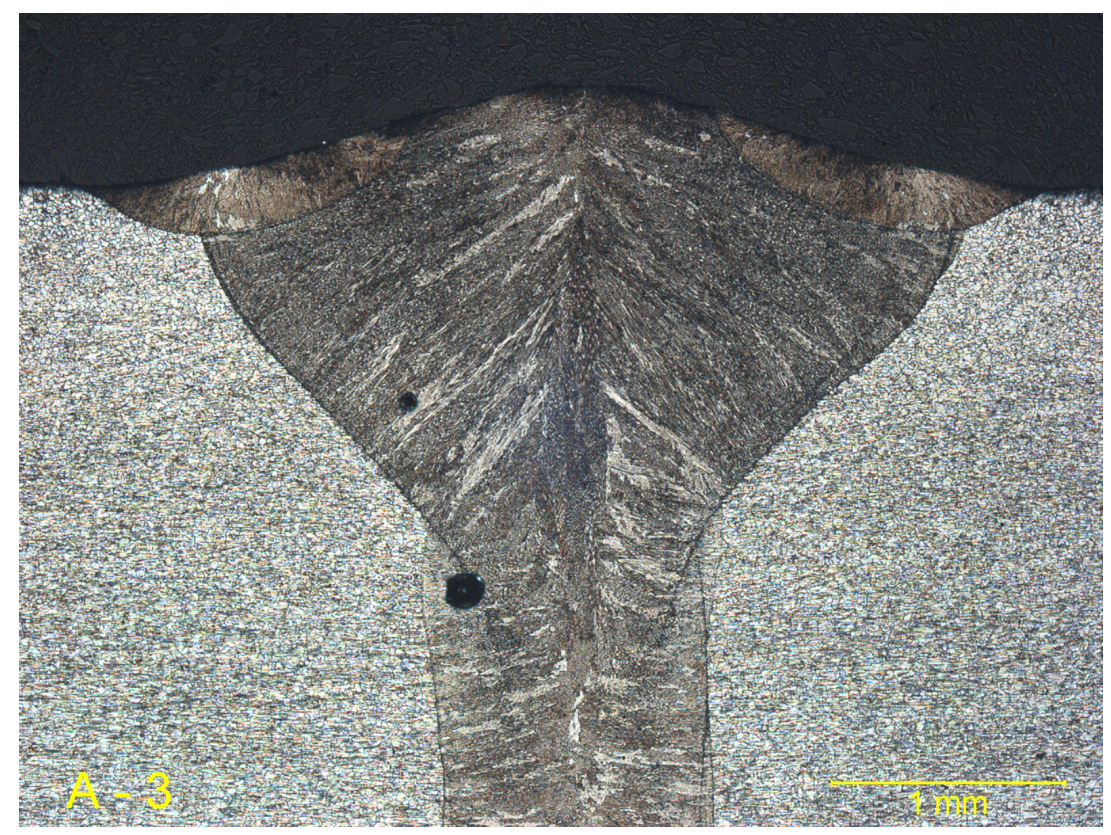

Figure 2.2 - Conduction Smoothing Welds Produced with Conventional Optics 


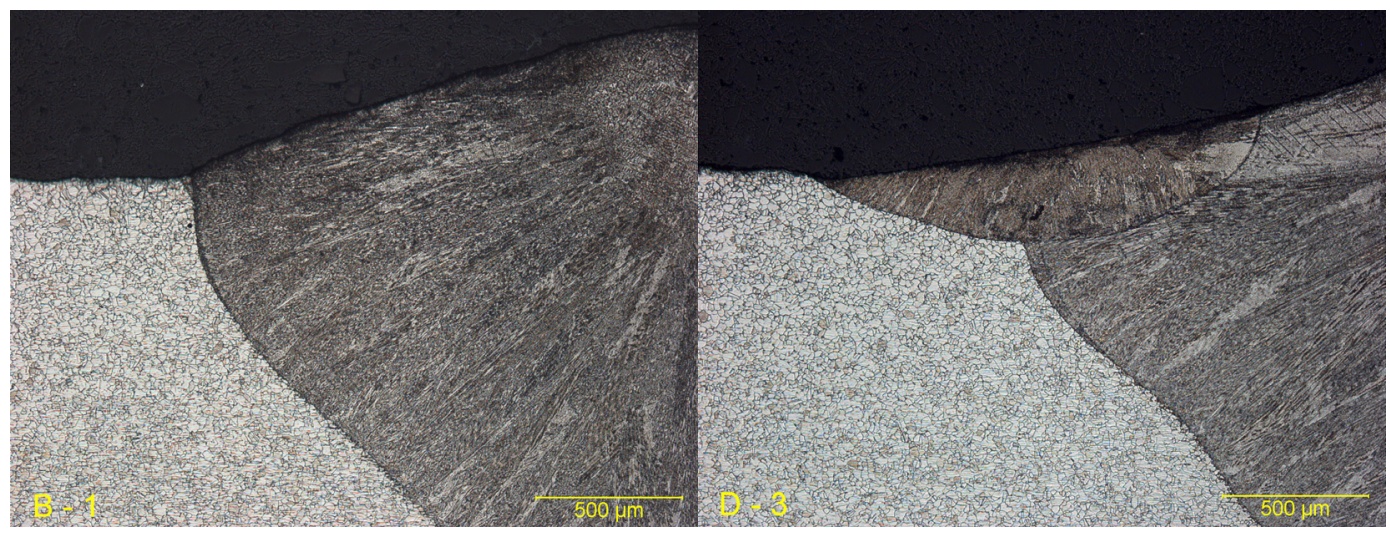

Figure 2.3 - Before and After Weld Toe Smoothing with Conventional Optics

\subsubsection{Characterization of Welding and Smoothing Beams}

With trials proving the feasibility of smoothing weld toes, the keyhole welding beam and the conduction smoothing beam were characterized to determine the constraints for the custom optic design. Using laser beam diagnostic tools from PRIMES GmbH [20], the power density and spot size of the beams was measured and recorded. Due to the high power density and small spot size, a PRIMES Focus Monitor was used to characterize the main beam. Because the smoothing beam had a larger spot size, a PRIMES Beam Monitor was needed to characterize the out of focus spot. For both beams, the measurements were taken at the welding plane. Figure 2.4 displays the results from the PRIMES beam measurement of the main beam. Figure 2.5 displays the results from the PRIMES beam measurement of the smoothing beam. The spot sizes and power densities are tabulated in Table 2.4. Additional PRIMES beam measurements can be found in Appendix A. With the feasibility of weld toe 
smoothing proven and the welding and smoothing beam profiles documented, the design of the custom three-spot optic could begin.

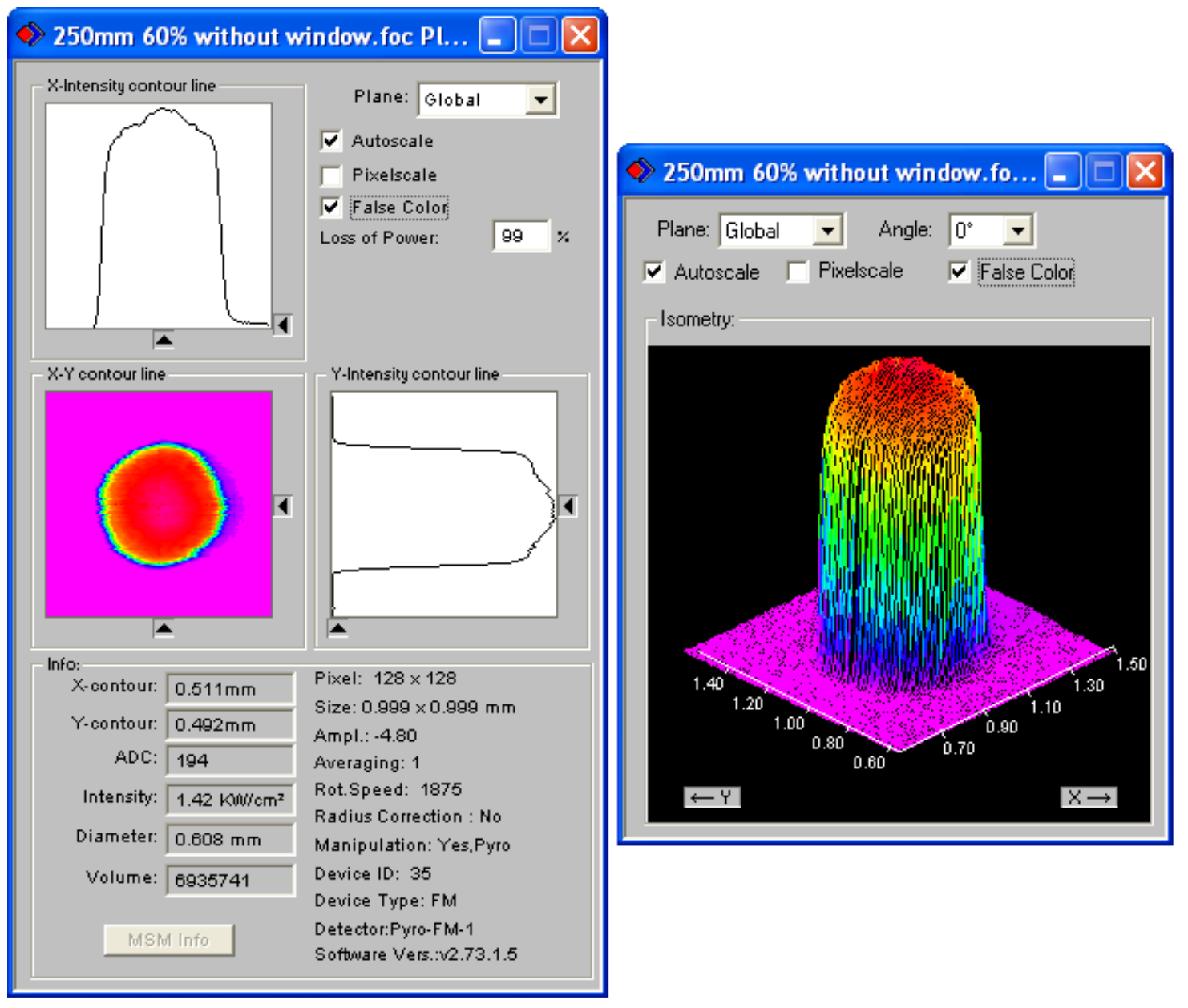

Figure 2.4 - PRIMES Measurement Results for the Main Beam 


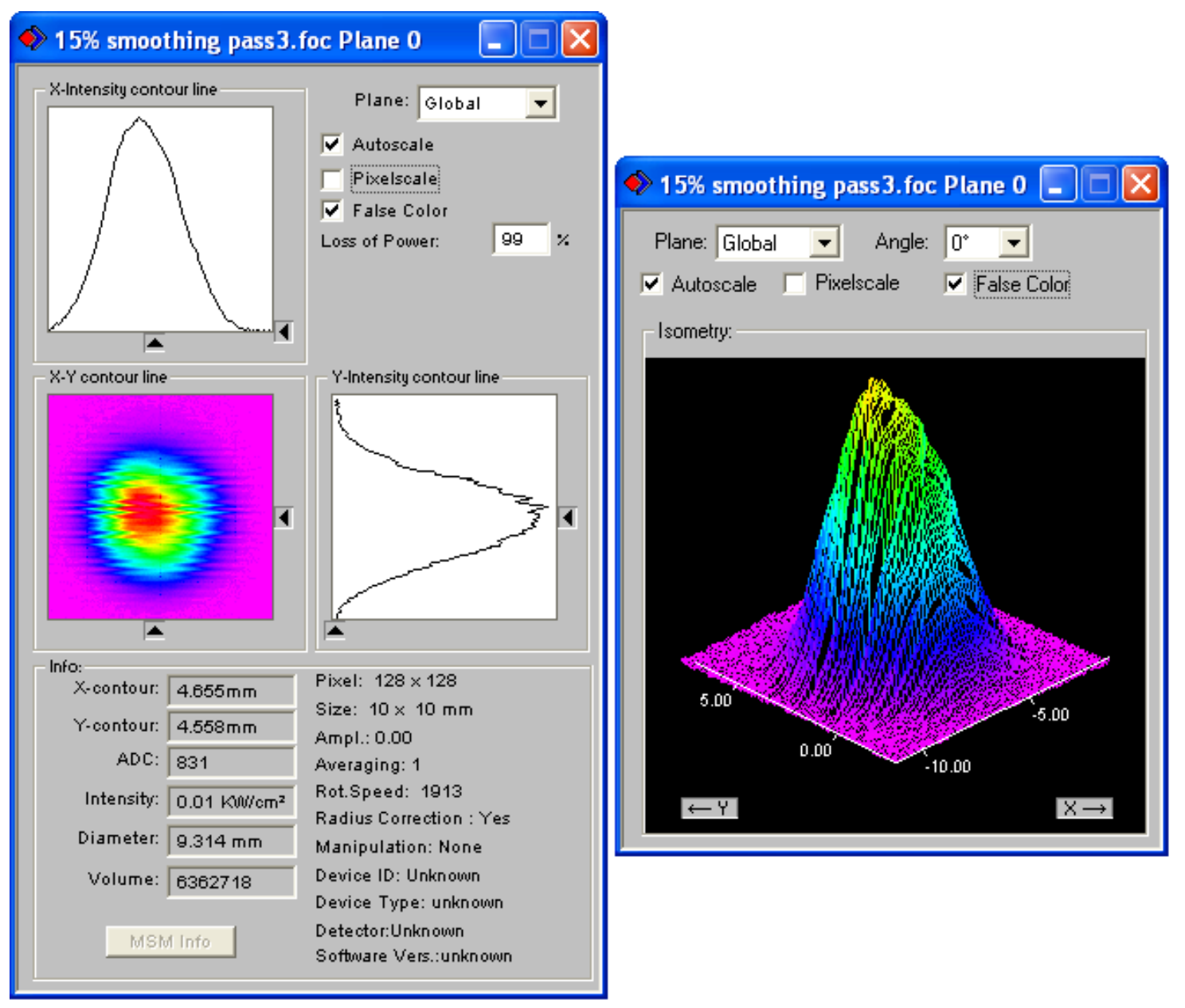

Figure 2.5 - PRIMES Measurement Results for the Smoothing Beam

\begin{tabular}{|c|c|c|}
\hline Welding Beam & $\begin{array}{c}\text { Spot Size } \\
(\mathrm{mm})\end{array}$ & $\begin{array}{c}\text { Power Density } \\
\left(\mathrm{kW} / \mathrm{cm}^{2}\right)\end{array}$ \\
\hline Main Beam & 0.498 & 3080.4000 \\
\hline Smoothing Beam & 6.198 & 4.9716 \\
\hline
\end{tabular}

Table 2.4 - PRIMES Beam Measurement Data 
In addition to the spot size and power density of each of the three beams, the relative location of each beam was also necessary for the design of the custom optic. The lateral spacing of the two smoothing beams was determined in previous trials by welding over the weld toes of the baseline welds. The width of the baseline welds depends on the power and travel speed used to produce the weld. This means that the custom optic would have to be designed for one scenario of welding parameters.

Determining the longitudinal spacing was more difficult. Because all of the preliminary proof-of-concept welding trials were produced with single-spot conventional optics, the main weld and surrounding base metal was relatively cool when the second and third passes were attempted. For the conduction beams of the custom optic to remelt and smooth the weld toes, the main weld needed to be mostly solidified prior to the smoothing passes. The longitudinal spacing from the main beam to the trailing beams was therefore determined by estimating the weld pool size and shape from the end crater produced during baseline welding tests with conventional optics. The distance from the beam to the back of the end crater was $10 \mathrm{~mm}$. The final parameters for all three beams are listed in Table 2.5. 


\begin{tabular}{|c|c|c|c|c|}
\hline Welding Beam & $\begin{array}{c}\text { Power } \\
(\mathrm{kW})\end{array}$ & $\begin{array}{c}\text { Power Density } \\
\left(\mathrm{kW} / \mathrm{cm}^{2}\right)\end{array}$ & $\begin{array}{c}\text { Relative } \\
\text { Power Ratio }\end{array}$ & $\begin{array}{c}\text { Relative Position } \\
\mathrm{X}, \mathrm{Y}(\mathrm{mm})\end{array}$ \\
\hline Main Beam & 6 & 3000 & 4 & 0,0 \\
\hline Smoothing Beam 1 & 1.5 & 5 & 1 & $1,-10$ \\
\hline Smoothing Beam 2 & 1.5 & 5 & 1 & $-1,-10$ \\
\hline
\end{tabular}

Table 2.5 - Design Parameters for Each Beam of the Custom Optic

\subsection{Custom Optic Design}

This custom optic solution was designed to be inserted into the current welding optics in use at EWI for ease and speed of integration. To produce three spots, the custom optic needed to have three optical surfaces with sharp transitions to each facet. This design could not be produced with conventional transmissive materials like quartz or manufacturing techniques such as grinding and polishing.

To be able to manufacture the custom optic and insert the optic into the current welding optics, it had to be machined from a transmissive optical material. Multi-spectral zinc sulfide (ZnS) is a relatively new optical material from II-VI, Inc [21]. It is II-VI Infrared's standard zinc sulfide material that has been treated by a hot isostatic press (HIP) process. With similar laser properties of other transmissive optical materials including minimal scatter, high thermal conductivity, and high transmission characteristics from 0.4 to 12 microns, $\mathrm{ZnS}$ is suitable for a variety of laser processing applications [22]. However, it is able to be machined by diamond turning unlike conventional quartz optics. With the 
ability to diamond machine $\mathrm{ZnS}$, a variety of custom beam shaping optics could be manufactured.

The custom optic was designed to fit into the collimated beam of the current configuration of welding optics at EWI. Figure 2.6 is an illustration of these optics, which use a combination of transmissive and reflective optics. The collimator is a $150-\mathrm{mm}$ plano-convex $\mathrm{ZnS}$ lens. The focusing optic is a $90-$ degree 250-mm parabolic copper mirror. The custom optic was to be inserted into the collimated beam path.

With the power density and beam spacing defined, a custom optic solution was modeled by Craig Walters Associates (CWA) [23] to produce a beam distribution similar to the experimentally determined beams. Using a ray tracing software program called ZEMAX ${ }^{\mathrm{TM}}$, CWA was able to model the beam path and output irradiance through a solid model of the custom optic. From this model, CWA made iterative adjustments until the output power distribution closely matched the results previously determined in the conventional optic welding trials. A drawing of the final design is shown in Figure 2.7.

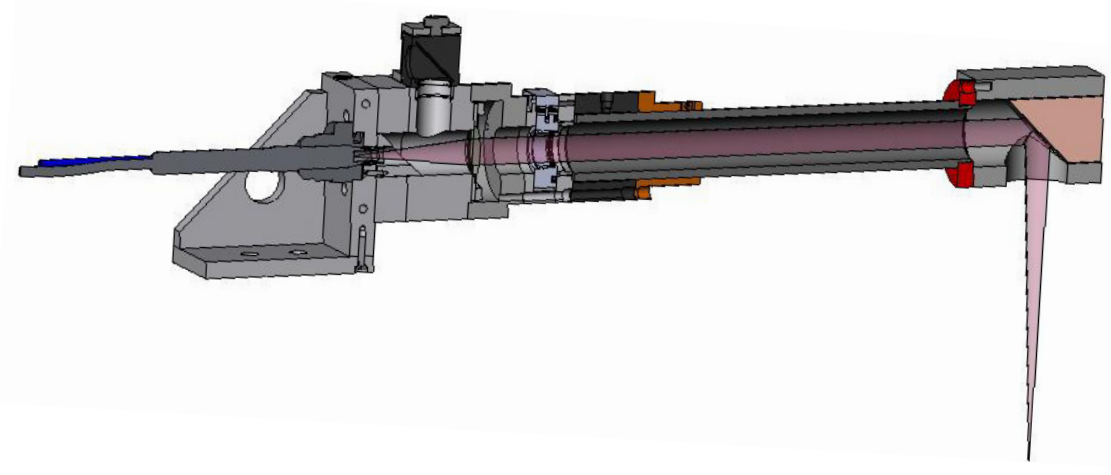

Figure 2.6 - Illustration of EWI "Conventional" 10-kW Welding Optics 


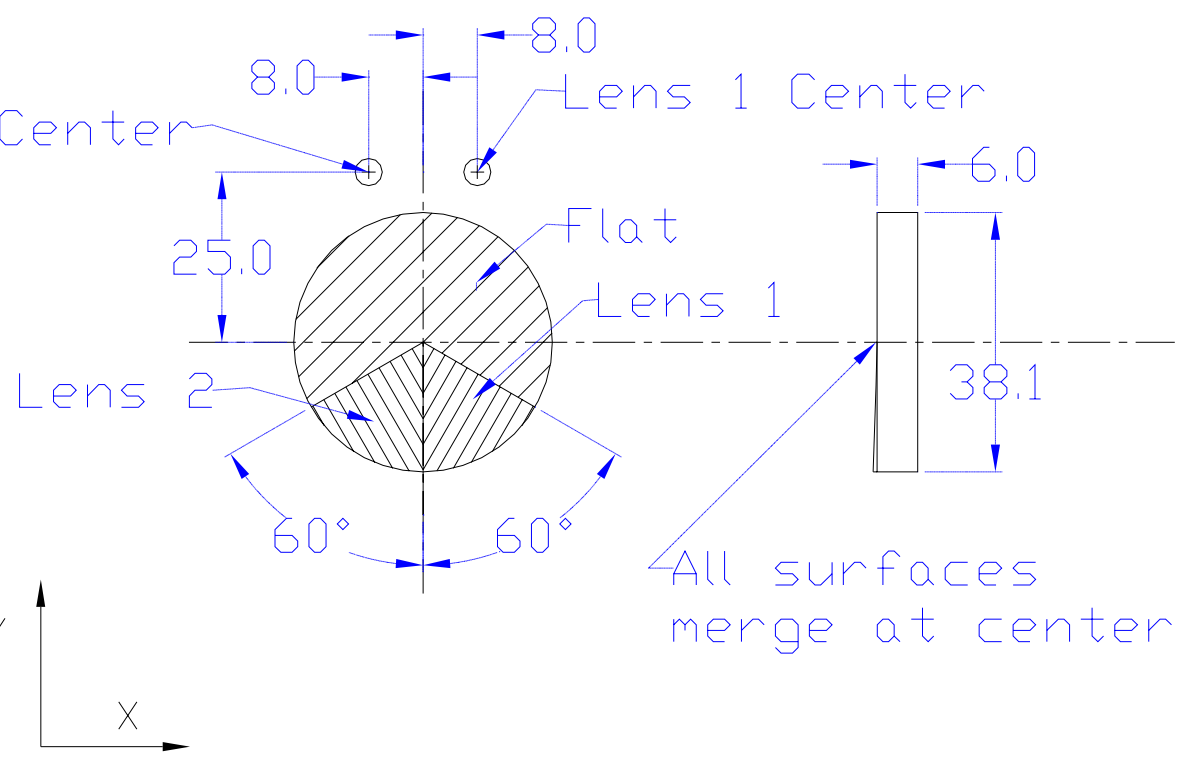

Figure 2.7 - Drawing of Custom Optic Final Design by Craig Walters Associates

The custom optic was designed as a $38 \mathrm{~mm}$ lens having a flat face on two thirds of the surface. This allowed $67 \%$ of the beam to travel through the custom optic unaltered. This $67 \%$ would then be focused by the copper mirror to become the main welding beam. The remaining 33\% of the power was deflected by the two sector-shaped lenslets to become the two trailing spots for smoothing the weld toes. This division would maintain a relative power ratio among the three spots similar to the ratio determined in the initial conventional optic trials.

To separate and shape the $33 \%$ of the beam to be used for weld toe smoothing, two lenslets were modeled on the custom optic. Each of these lenslets occupies a 60-degree sector of the total optic and has a biconic curvature to direct and shape the trailing beams. Due to the complexity of 
designing and machining a custom optic that could produce two defocused spots separated from the main beam and each other by a specified distance, the trailing spots were designed to have a triangular shape at the welding plane rather than round spots.

Figure 2.8 shows a model of the predicted power distribution of the custom optic design. Figure 2.9 is an illustration of the ray tracing generated by ZEMAX $^{\mathrm{TM}}$. The optic was designed to operate in the collimated beam path of the conventional optics as in Figure 2.9. Figure 2.10 shows a rendered image of a solid model of the optic.

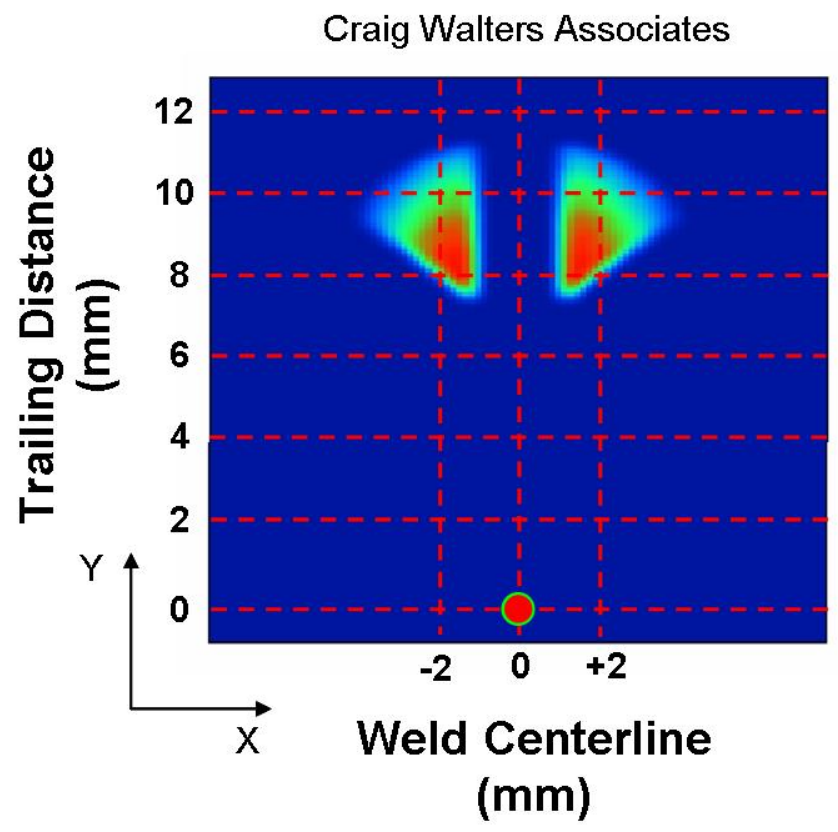

Figure 2.8 - Predicted Power Distribution of the Custom Optic Final Design by Craig Walters Associates 


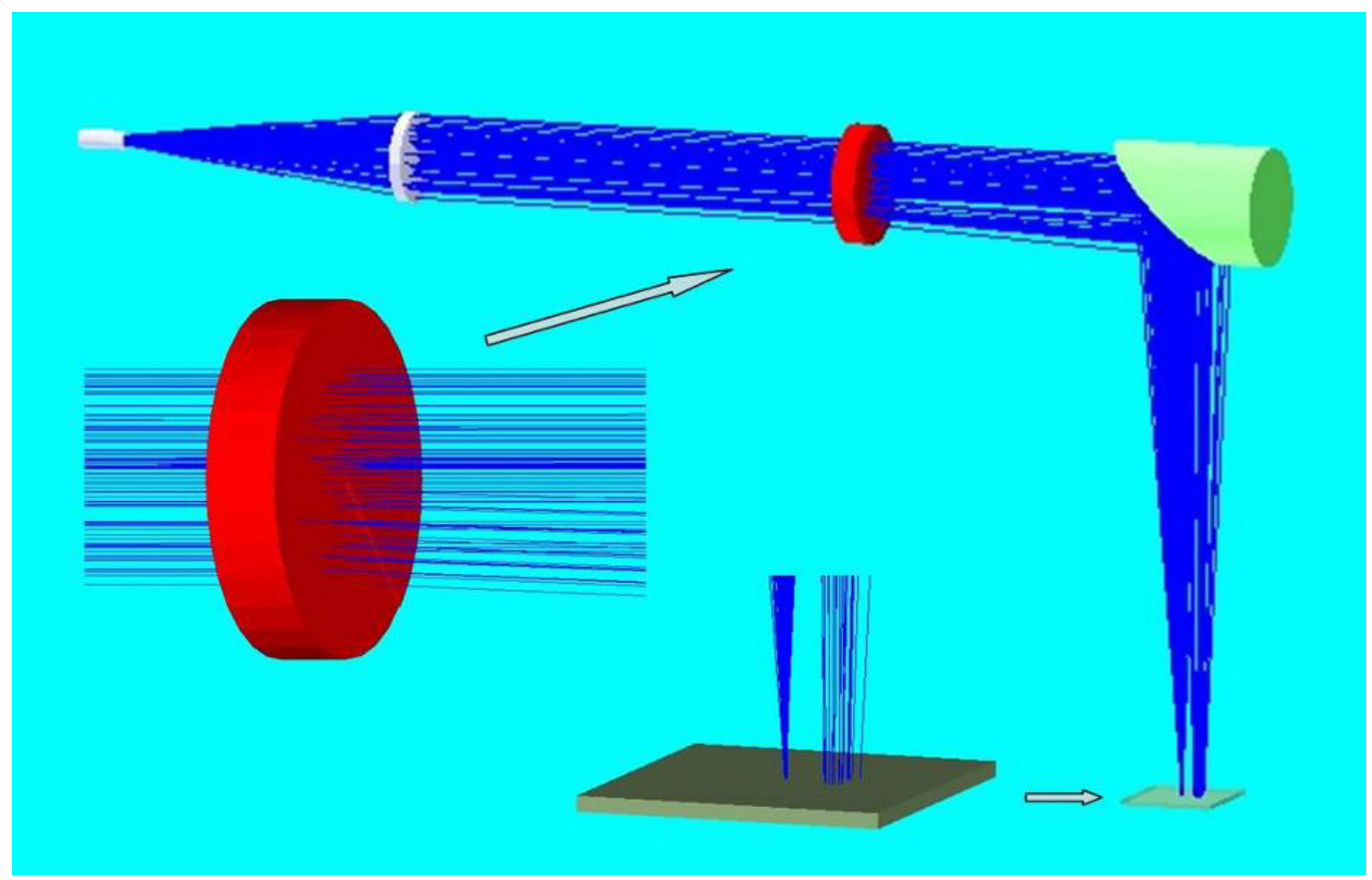

Figure 2.9 - Ray Trace Generated in ZEMAX ${ }^{\mathrm{TM}}$ by Craig Walter Associates

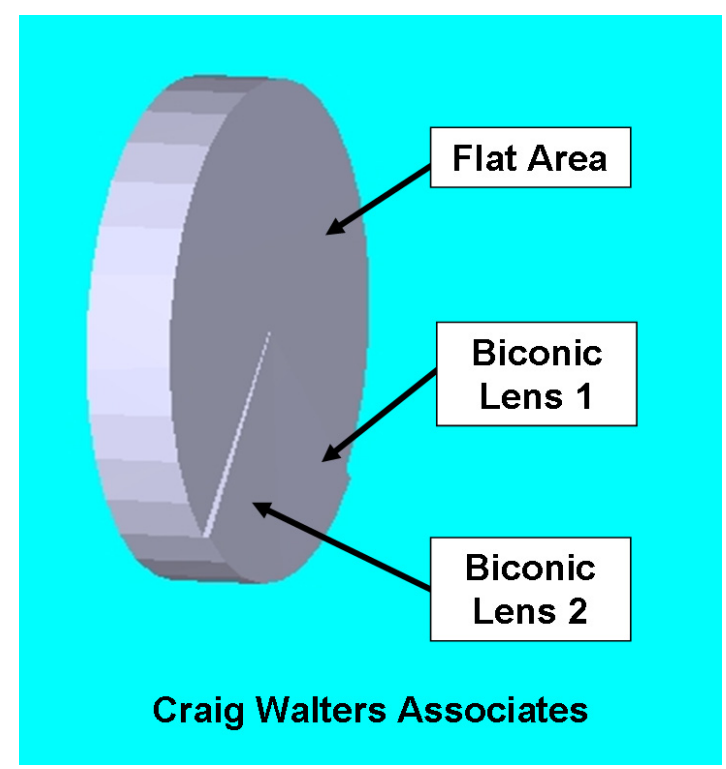

Figure 2.10 - Solid Model of Custom Three-Spot Optic by Craig Walters Associates 
The finalized design was then sent to II-VI, Inc. to be manufactured from ZnS. The biconic lenslets were cut with a fast-axis diamond machining system. Once the two curvatures had been cut, the flat section was fly cut to define the sectors. A photo of the resulting optic can be seen in Figure 2.11.

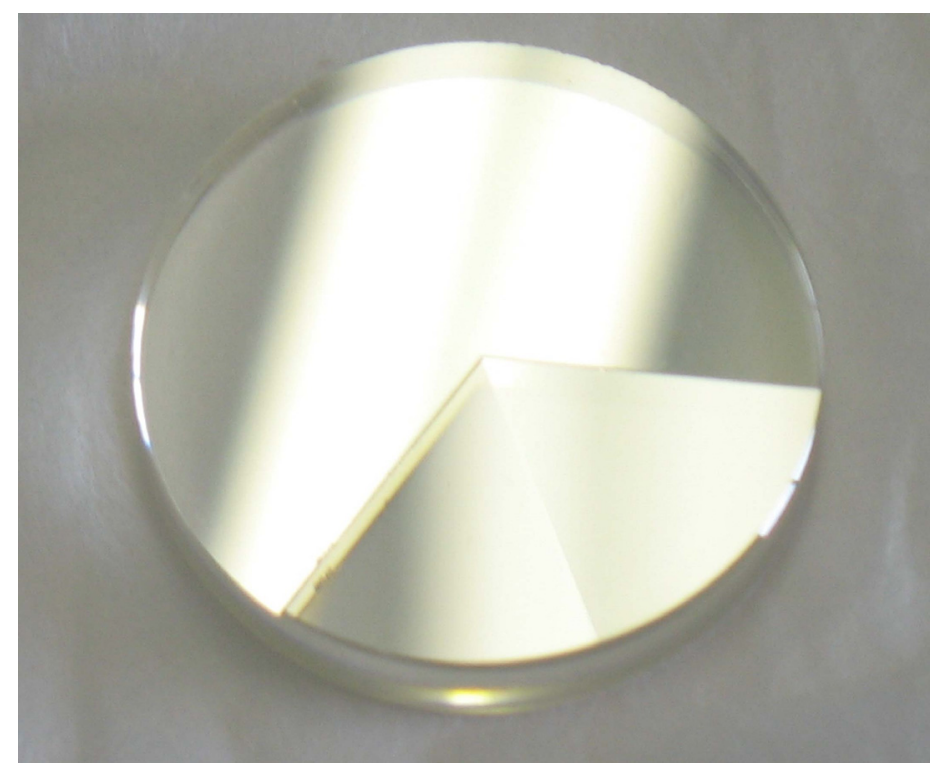

Figure 2.11 - Photo of the Finished Custom Three-Spot Optic Manufactured by II-VI, Inc.

Although $\mathrm{ZnS}$ is diamond machinable, the complexity of the design of this custom optic was pushing the envelope of lens manufacture. Each of the two lens sectors was designed to have a biconic curvature of $2200 \mathrm{~mm}$ in the $\mathrm{X}$ axis and $1100 \mathrm{~mm}$ in the $\mathrm{Y}$ axis. After machining, the radii were measured to be 2201 $\mathrm{mm}$ in the $\mathrm{X}$ axis and $1099 \mathrm{~mm}$ in the $\mathrm{Y}$ axis. Each of the sectors was to occupy 60 degrees of the total optic. However, the final dimensions of the sectors were machined as 55 and 64 degrees. The remaining 240 degrees of the optic were 
designed to be a flat surface to let the beam pass through unaltered. However, the machined surface was not perfectly flat. Figure 2.12 shows the two passes of the fly cutting process were not parallel.

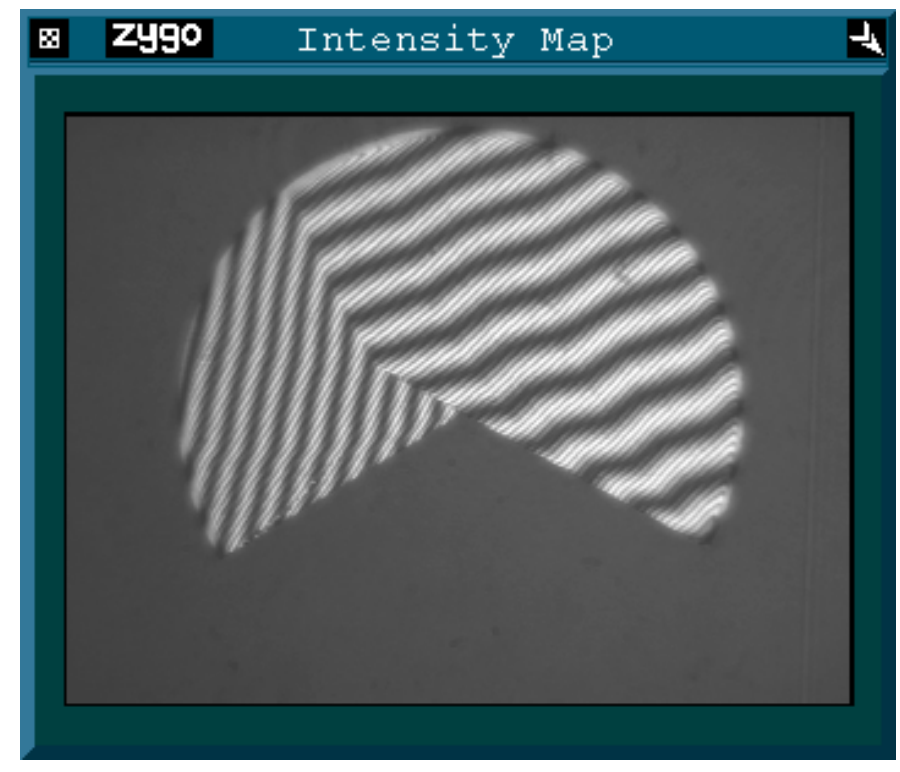

Figure 2.12 - Interferometer Measurement of Flat Surface of Custom Optic Reported by II-VI, Inc. 


\section{CHAPTER 3}

\section{CUSTOM OPTIC TESTING AND WELDING}

To test and weld with the custom optic, an alignment mechanism was built to house and position the custom optic within the EWI welding optics. The alignment of the optic was tested, and laser power measurements were taken to test the power loss through the custom optic. Welding trials were then conducted with the custom optic and compared to the performance of conventional optics.

\subsection{Custom Optic Testing}

Because the three spots were directional, the asymmetric optic had to be aligned to the collimated beam in three axes. The three axes of motion included two translation directions in the plane of the optic surface and rotation of the optic coaxial to the beam. Since the alignment of the custom optic was critical for the location and power distribution of the three spots, the optic mount needed to be capable of fine adjustment in each of these three axes.

Translation of the optic relative to the beam in the $\mathrm{X}$ axis adjusted the power ratio between the two trailing sectors. Translation of the optic relative to the beam in the $Y$ axis adjusted the power ratio between the main beam and the trailing sectors. Rotational adjustment of the optic coaxial to the beam affected 
the shape of the trailing sectors as well as the location of the sectors relative to the main beam.

In addition to the precision alignment relative to the beam, the optic mount also needed to be water-cooled to be able to operate at $10 \mathrm{~kW}$. Figure 3.1 is a model of the custom optic alignment system designed by EWI. Once the alignment system was completed, the custom optic was installed and the alignment system was added to the welding optics. Figure 3.2 is a photo of the alignment mechanism installed in the EWI welding optics.

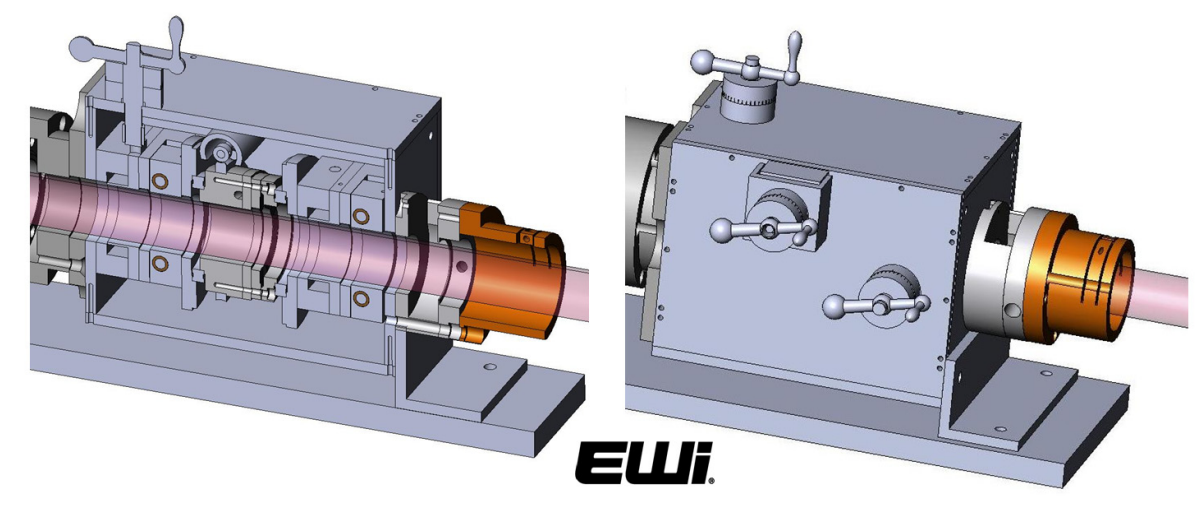

Figure 3.1 - Illustration of Custom Optic Alignment Mechanism 


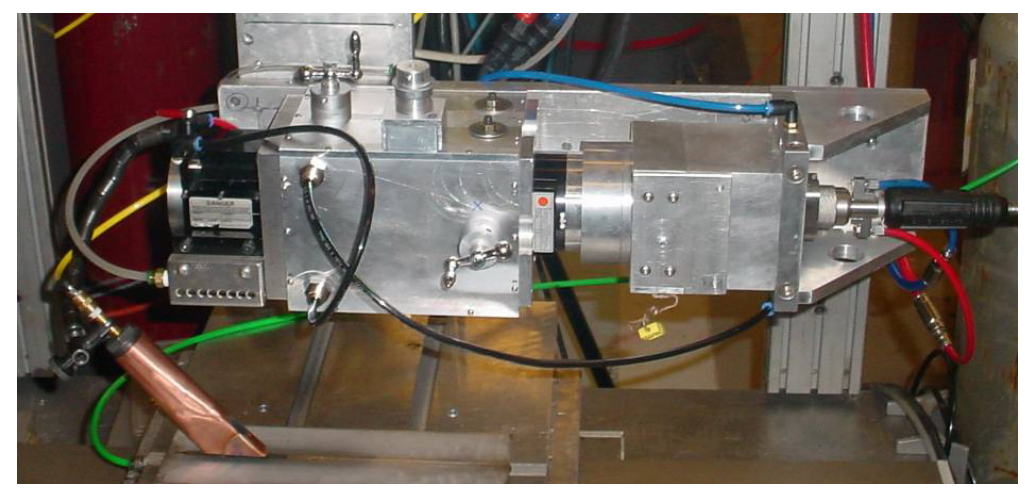

Figure 3.2 - Photo of the Installed Optic Alignment System

With the custom optic and the water-cooled alignment system installed, the equipment was subjected to power tests. The continuous wave output power of the entire optical system was measured at the work from 1 to $10 \mathrm{~kW}$. The custom three-spot optic caused an average of $2.1 \%$ loss compared to the output power of the system without the custom three-spot optic. These power measurements are listed in Appendix B. To test for possible damage at high transmitted power, the optical system was tested at $10 \mathrm{~kW}$ for one minute. No damage to the optic or excessive heat in the system was observed.

Since the shape of the three spots was complex, the longitudinal spacing of the spots was large, and the power density varied greatly, the PRIMES laser beam diagnostic tools could not be used to map the power distribution of all three spots together. To capture a general understanding of the location of the three spots, the laser was fired at low power onto laser shot paper at focus. The focus was determined to be the typical focal position of the main beam, or $250 \mathrm{~mm}$ from the parabolic focusing mirror. This paper burn verified that the custom optic was producing a spatial distribution similar to the proposed three spots. 
To more accurately observe the relative spacing and power density of the three spots, burn shots were fired onto black polyethylene. When a high-power, short pulse hit the black plastic, some of the plastic was vaporized. The depressions remaining in the plastic were an indication of the spacing and power distribution of the three spots. Figure 3.3 is an example of a test burn on the black polyethylene material.

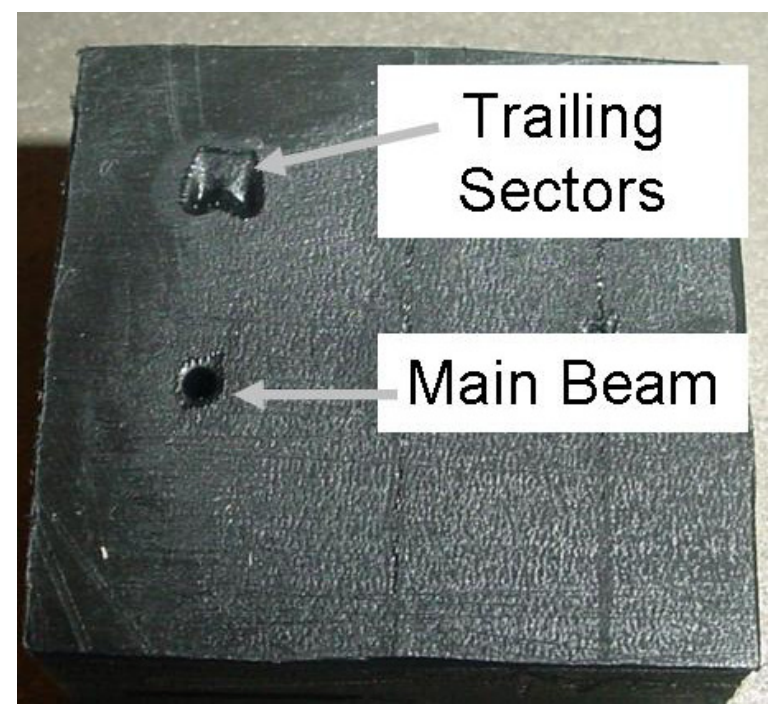

Figure 3.3 - Photo of Burn Shot from Custom Optic on Black Polyethylene

To test the alignment of the optic, multiple burn shots were conducted on the black polyethylene. Each axis was incrementally adjusted between shots. The increments of motion in the $X$ and $Y$ axes were $1 \mathrm{~mm}$. Rotation was adjusted in $2.25^{\circ}$ increments. The burn marks on the black plastic were then compared to determine the best alignment. Figure 3.4 is a photo of the results from the burn shots conducted on black polyethylene. The depressions produced by vaporization were painted white for contrast. 


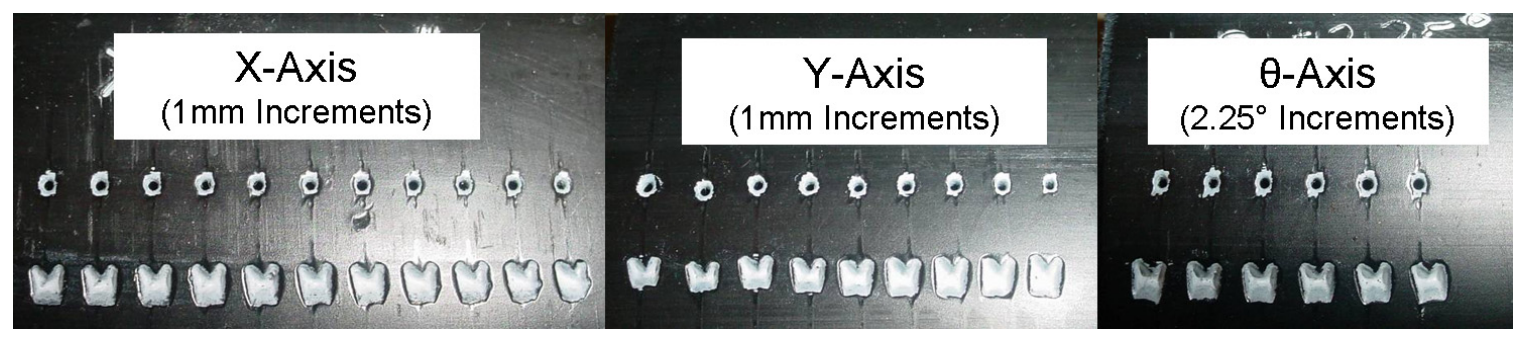

Figure 3.4 - Plastic Burn Shots for Alignment of Each Axis (Painted White for Contrast)

From the burn shots, it was observed that the trailing sectors in fact overlap. Rather than being separated by some distance, the sectors overlap to form one trailing shape. Also, this trailing shape was only $6 \mathrm{~mm}$ behind the main beam rather than the proposed $10 \mathrm{~mm}$. In an attempt to correct these issues, more burn shots were conducted at varying focal distances. The entire optic system was moved vertically in 1-mm increments to change the focal distance.

When the focal distance was increased by $4 \mathrm{~mm}$, the trailing sectors were still overlapped; however, the distance between the main beam and the trailing sectors had increased to $8 \mathrm{~mm}$. Changes in focal distance greater than $4 \mathrm{~mm}$ above or below focus altered the shape of the main beam. It was presumed that welding farther than $4 \mathrm{~mm}$ from the focus of the main beam would be detrimental to weld penetration. Since the gain in the distance between the main spot and the trailing spots was minimal, the best focal position for welding was determined to be at the focus of the main beam, or $250 \mathrm{~mm}$ from the parabolic focusing mirror. With the best alignment determined from burn shots, welding trials were conducted with the custom three-spot optic. 


\subsection{Custom Optic Welding Trials}

From the burn shots on the black plastic, the resulting power distribution from the custom optic was found to be different from the designed distribution. However, welding trials were attempted with the custom optic. As with the conventional optic trials, partial penetration welds were completed on 8-mm 304 stainless steel in the bead-on-plate configuration with industrial grade argon shielding.

In the conventional optic trials, the best parameters were determined to be $6 \mathrm{~kW}$ of laser power at $120 \mathrm{ipm}$ travel speed (listed in Table 2.2). Welding trials with the custom optic were conducted at $120 \mathrm{ipm}$ travel speed with $9 \mathrm{~kW}$ of laser power. This would match the travel speed of the baseline trials and also would produce approximately $6 \mathrm{~kW}$ in the main beam. In addition to replicating the baseline conditions, other laser powers and travel speeds were tested. These parameters are listed in Table 3.1.

\begin{tabular}{|c|c|c|c|}
\hline $\begin{array}{c}\text { Travel Speed } \\
\text { (ipm) }\end{array}$ & $\begin{array}{c}\text { Laser Power } \\
(\mathrm{kW})\end{array}$ & $\begin{array}{c}\text { Focal Length } \\
(\mathrm{mm})\end{array}$ & Focal Position \\
\hline 120 & 8 & \multirow{2}{*}{250} & Part surface \\
\hline 160 & 9 & & \\
\hline 200 & 10 & & \\
\hline
\end{tabular}

Table 3.1 - Variables Investigated for Welding with Custom Three-Spot Optic

From the welding trials with various laser power and travel speed combinations performed in the custom optic welding trials, the optic proved to be 
successful in producing a smoother weld surface than conventional optics. The optic was designed to produce three spots in the goal of producing three weld pools: the main weld pool and two conduction-limited weld pools trailing over the weld toes. Instead, the actual power distribution consisted of two spots. The main beam was as designed; however, the trailing spots overlapped into one beam shape.

During welding trials, the custom optic produced one weld pool rather than the proposed three. This can be attributed to the main beam producing an unknown interpass temperature at the point of the trailing sectors as well as the shorter longitudinal spacing of the trailing sectors behind the main beam from the proposed spacing of $10 \mathrm{~mm}$.

Although the trailing sectors overlapped each other and the longitudinal spacing from the main beam was shorter than designed, the custom optic welding trials did show an improvement over the conventional optic welds. Of the parameters tested, all showed a reduction in bead convexity and an improvement in weld toe angels compared to the baseline conventional optic welds while maintaining similar penetration. For this reason, the optimum parameters were selected to have a travel speed identical to the baseline conventional optic parameters and produce a similar penetration. Table 3.2 lists these parameters. Figure 3.5 is a comparison of a conventional optic weld to a custom optic weld. 


\begin{tabular}{|c|c|c|c|c|c|c|}
\hline $\begin{array}{c}\text { Travel } \\
\text { Speed } \\
(\mathrm{ipm})\end{array}$ & $\begin{array}{c}\text { Laser } \\
\text { Power } \\
(\mathrm{kW})\end{array}$ & $\begin{array}{c}\text { Fiber } \\
\text { Diameter } \\
(\mu \mathrm{m})\end{array}$ & $\begin{array}{c}\text { Collimation } \\
\text { Distance } \\
(\mathrm{mm})\end{array}$ & $\begin{array}{c}\text { Focusing } \\
\text { Distance } \\
(\mathrm{mm})\end{array}$ & $\begin{array}{c}\text { Spot } \\
\text { Size } \\
(\mu \mathrm{m})\end{array}$ & $\begin{array}{c}\text { Focal } \\
\text { Position }\end{array}$ \\
\hline 120 & 10 & 300 & 150 & 250 & Custom & $\begin{array}{c}\text { Part } \\
\text { surface }\end{array}$ \\
\hline
\end{tabular}

Table 3.2 - Welding Parameters for Custom Three-Spot Optic

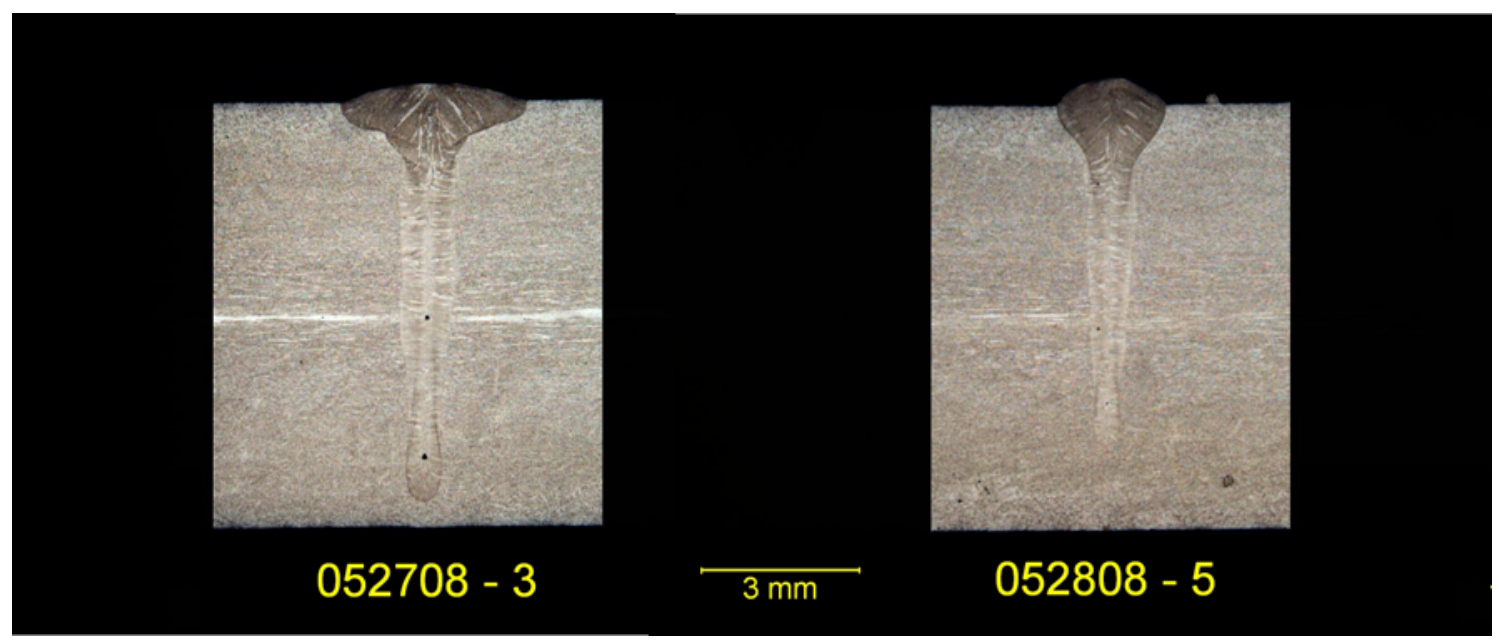

Figure 3.5 - Comparison of Custom Optic Weld Cross Section (left) to Conventional Optic Weld Cross Section (right)

Because the trailing shape was closer than designed and the interpass temperature of the weld was higher than during the conventional optic trials, the custom beam shape produced one weld pool instead of the designed three.

Figure 3.6 is a photo of end craters produced during custom optic welding trials. The end craters show a representative shape of the melt regions produced from the power distribution of the custom optic. Although there appears to be one weld pool, the pool has two distinct melt shapes: one produced by the main beam and one produced by the trailing shape. The extra heat provided by the 
trailing beam shape melted more of the base material surface and improved the smoothness of the weld bead surface. Figure 3.7 is a magnified view from a cross section of the weld surface produced in with the custom optic. This section shows the penetration depth and fusion profile of the melt zone produced by the trailing shape.

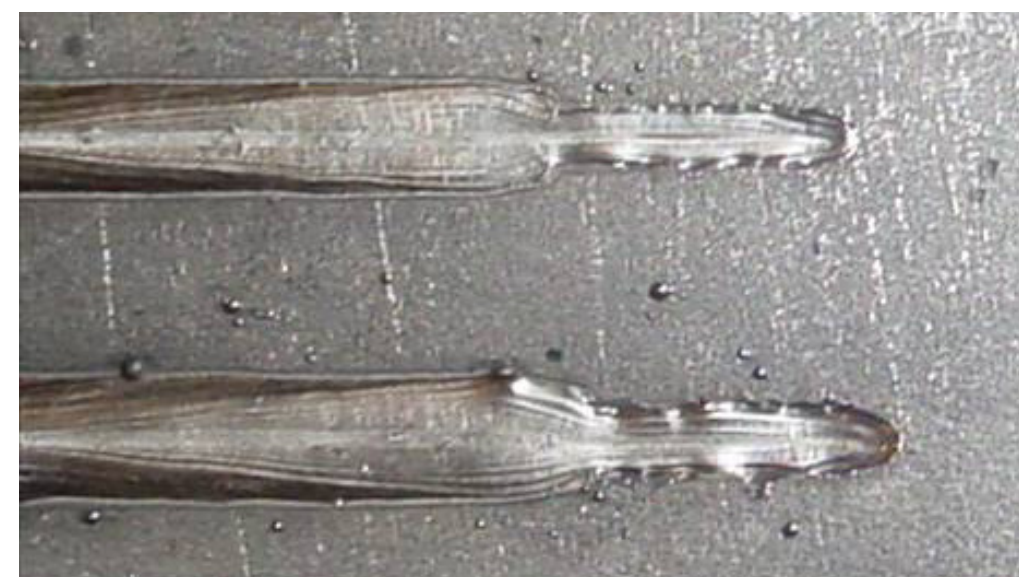

Figure 3.6 - Photo of Weld End Craters Produced with the Custom Optic

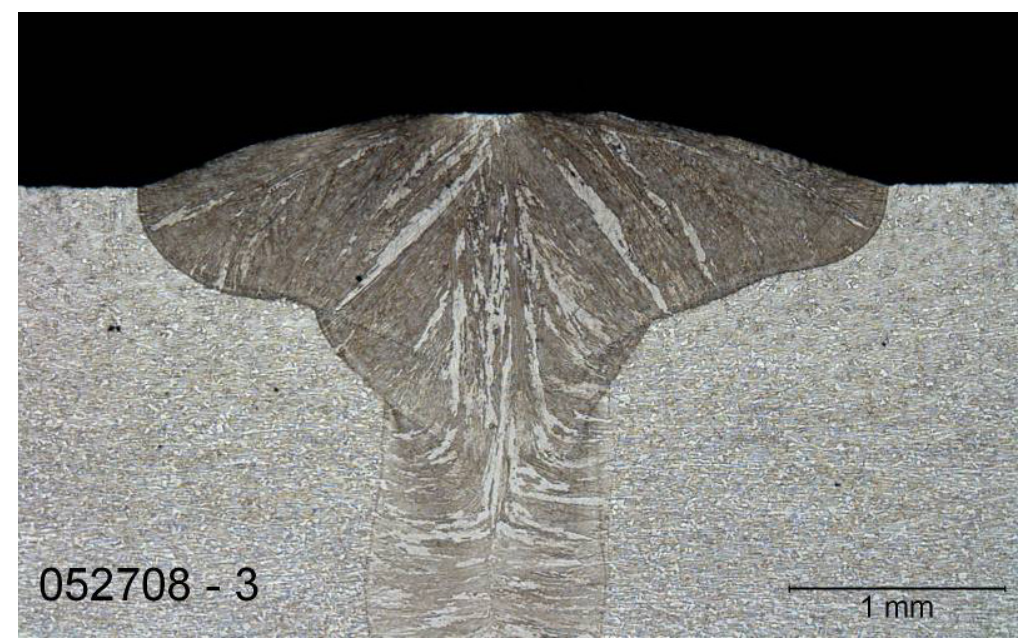

Figure 3.7 - Cross Section of Custom Optic Weld 
Using Image-Pro ${ }^{\circledR}$ image analysis software, the weld toe angles for conventional optic and custom optic welds were measured. The weld toe measurements are listed in Table 3.3. Welding with conventional optics produced average toe angels of $125^{\circ}$, while welding with the custom optic produced average weld toe angles of $163^{\circ}$. Despite differences from proposed design, the custom optic was able to produced improved toe angles and smoother bead surface than the conventional optics.

\begin{tabular}{|c|c|}
\hline $\begin{array}{c}\text { Conventional Optic } \\
\text { Toe Angles } \\
\left({ }^{\circ}\right)\end{array}$ & $\begin{array}{c}\text { Custom Optic Toe } \\
\text { Angles } \\
\left({ }^{\circ}\right)\end{array}$ \\
\hline 115 & 165 \\
\hline 140 & 160 \\
\hline 120 & 165 \\
\hline 125 & 165 \\
\hline 128 & 157 \\
\hline 136 & 163 \\
\hline 114 & 159 \\
\hline 139 & 158 \\
\hline 119 & 170 \\
\hline 118 & 165 \\
\hline
\end{tabular}

Table 3.3 - Comparison of Weld Toe Angle Measurements

In previous research by Cho et. al., weld toe angles of GMAW fillet welds were improved by the addition of a laser heat source. A defocused laser spot was positioned on the base metal flange approximately $10 \mathrm{~mm}$ from the GMAW electrode. This extra heat source spread the molten weld deposit over a larger area increasing the leg length of the fillet weld. With the increase in leg length 
from the laser addition, the weld toe angle also increased. This "laser-wetted" toe angle was $157^{\circ}$ as compared to the "non-wetted" toe angle of $132^{\circ}$ [13]. Laser wetting was also shown to improve the toe angle in the flat welding position (1F) to $172^{\circ}$ compared to the non-wetted toe angle of $154^{\circ}$ [13].

In this research, a custom optic was designed to produce a custom spatial and irradiance profile at the work. With this custom beam shape, welding trials were conducted to improve the weld toe angle for fatigue performance. By reducing geometric stress concentrations in a welded structure, the fatigue performance of the structure can be improved. The custom laser welding optic designed in this research may produce a welded structure with an improved fatigue life over a weldment produced with conventional laser welding optics. 


\section{CHAPTER 4}

\section{CONCLUSIONS AND FUTURE WORK}

The baseline welds produced using conventional optics did not exhibit any measureable undercutting at the weld toes; however, convex weld beads were produced with an average weld toe angle of 125 degrees. The proposed power distribution of the custom optic was designed to be three individual beams to produce three separate weld pools. The actual power distribution was two beam shapes: one main welding beam and one trailing beam shape formed by the overlapping of the two trailing sectors. Regardless of the differences from the designed beam shape, welds produced with the custom optic showed an improvement in weld toe angle to an average of 163 degrees.

\subsection{Conclusions}

From the research documented in this report, the following conclusions can be drawn.

1. Designing and manufacturing a complex transmissive zinc sulfide optic to produce a custom power distribution at the work is feasible.

2. Smoothing the surface of a weld in-process with a trailing beam is possible in a single pass. 
3. Compared to welding with conventional "single-spot" optics, welding with the custom optic showed a reduction in weld bead convexity and improved the average weld toe angles from 125 to 163 degrees.

\subsection{Future Work}

To simplify future iterations of this single pass smoothing optic, the trailing sectors should be redesigned as one beam shape rather than two. The optic should be designed so that movement of the optic can adjust the spacing between the main beam and the trailing beam shape. This would make the custom optic more versatile for different power levels and travel speeds. Instead of being one optic that transmits all of the beam power, the custom optic could be a transmissive wedge that would only occupy a small section of the collimated beam. To adjust the power ratio between the main beam and the trailing beam, the wedge would be moved in and out of the collimated beam.

In this research, the position of the trailing beams behind the main beam was determined by estimating the weld pool geometry from the end crater. For future work, this distance could be better estimated by modeling the temperature profile of the weld at various distances behind the main beam. With this information, the necessary location of the trailing beam could be better

determined. Additionally, the necessary heat input and thus power density of the trailing conduction weld could be modeled to aid in the design of the custom optic. 
All of the welding trials in this research were completed on stainless steel. Stainless steel is not overly sensitive in fatigue failures caused by geometric stress concentrations. Instead of stainless steel, future welding trials should be conducted on a more applicable material such as titanium. The titanium welds produced with conventional optics should be cross sectioned and compared to welds produced with the custom optic. The welds produced with each optic should then be fatigue tested to prove the effect of weld toe angle on fatigue life. 


\section{LIST OF REFERENCES}

1. American Welding Society (1991). "Welding Handbook", Volume 2, Eighth Edition, Chapter 22: Laser Beam Welding.

2. Steen, W. (2003). Laser Material Processing, Third Edition, Chapter 4: Laser Welding.

3. Laser Institute of America (2001). "LIA Handbook of Laser Material Processing", First Edition, Chapter 4: Components for Laser Materials Processing Systems.

4. Shealy, D. "Historical Perspective of Laser Beam Shaping", Proceedings of SPIE, Seattle, USA, July $9-11,2002$, Volume 4770, $28-47$.

5. Dickey, F., Weichman, L., Shagam, R. "Laser Beam Shaping Techniques", Proceedings of SPIE, Santa Fe, USA, April $24-28,2000$, Volume 4065, $338-348$.

6. Webb, C. and Jones, J. (2004). "Handbook of Laser Technology and Applications" Volume 2, Part C, Chapter 4: Beam Delivery, 1442.

7. Killpatrick, D. "Laser Beam Shaping Takes the Next Step", Industrial Laser Review, July 1993, 8 (7), 18.

8. Liu, Y., Kannatey-Asibu, E. "Characteristics of Elliptical Laser Beam Preheating During Laser Welding", Manufacturing Science and Engineering, ASME, 1993, Volume 64, 895 - 905.

9. Liu, Y., Kannatey-Asibu, E. "Experimental Study of Dual-Beam Laser Welding of AISI 4140 Steel”, Welding Journal, September 1997, 342 - 348.

10. Russ, A., Gref, W., Leimser, M., Dausinger, F., Hugel, H., "Double Focus Technique - Influence of Focal Distance on the Welding Process", Proceedings of SPIE, Moscow, Russia, June $22-27,2002$, Volume 5121, $362-368$.

11. Kell, J., Tyrer, J., Higginson, R., Thomson, R., Jones, J., Noden, S., "Holographic Diffractive Optical Elements Allow Improvements in Conduction Laser Welding of Steels", Proceedings of ICALEO, Scottsdale, AZ, USA, 2006, 8 - 17. 
12. Hammond, J., Johnson, E., Koehler, C., Stack, J., Suleski, T., "Diffractive Optics for Laser Welding and Bonding", Proceedings of SPIE, San Jose, CA, USA, January 27 - 29, 1999, Volume 3633, $206-213$.

13. Cho, M.H., Farson, D., Lim, Y.C., Choi, H.W., "Hybrid Laser/Arc Welding Process for Controlling Bead Profile", Science and Technology of Welding and Joining, 2007, 12 (8), $677-688$.

14. Choi, H.W., Farson, D., Cho, M.H., "Using a Hybrid Laser plus GMAW Process for Controlling the Bead Humping Defect", Welding Journal, August 2006, $174-179$.

15. Cho, M.H., Farson, D., "Simulation Study of a Hybrid Process for the Prevention of Weld Bead Hump Formation", Welding Journal, September $2007,253-262$.

16. Mombo-Caristan, J., Mueller, R., Sharp, C., McCay, M., "Parabolic Mirror Adapted-Alignment for High Speed-High Power Laser Welding with an Oblong Focused Beam Spot", Proceedings of ICALEO, 1997, Section G, 191-199.

17. Banas, C. High Power Laser Welding. The Industrial Laser Annual Handbook. Penn Well Books, 1986.

18. Hsu, R., Fliss, S., Heinemann, S., "Aluminum Tailored Blank Welding Using Laser Beam Shaping and Twin-Spot Optics", Proceedings of ASME Manufacturing in Engineering Division, Orlando, FL, USA, November 5 - 10, 2000, Volume 11, $967-971$.

19. Edison Welding Institute (EWI), 1250 Arthur E. Adams Drive, Columbus, $\mathrm{OH}$ 43221. (614) 688-5000. <http://www.ewi.org>.

20. PRIMES GmbH, Max-Planck Strasse 2, D - 64319 Pfungstadt, Germany. +49 6157 / 9878-0. <http://www.primes.de>.

21. II-VI, Inc., 375 Saxonburg Boulevard, Saxonburg, PA 16056. (724) 3524455. <http://www.ii-vi.com>.

22. II-VI, Inc., II-VI Infrared. "Zinc Sulfide MultiSpectral (ZnS MS)", 2009. 8 Feb 2009 <http://www.iiviinfrared.com/zinc_sulfide_multispectral_znsms>.

23. Craig Walters Associates, 400 Fox Run, Powell, OH 43065. (614) 846-8478. 


\section{APPENDIX A}

\section{PRIMES BEAM DIAGONOSTIC MEASUREMENTS}




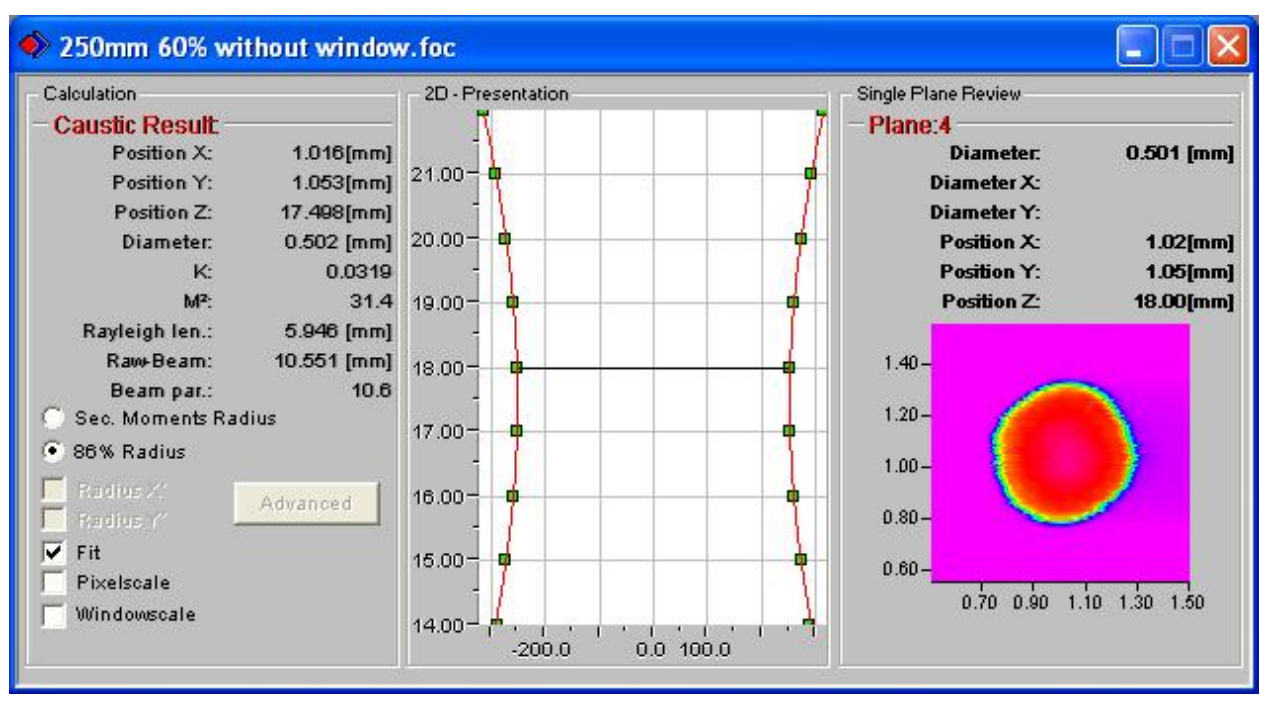

Figure A.1 - Caustic Measurement of Main Welding Beam from Conventional Optics

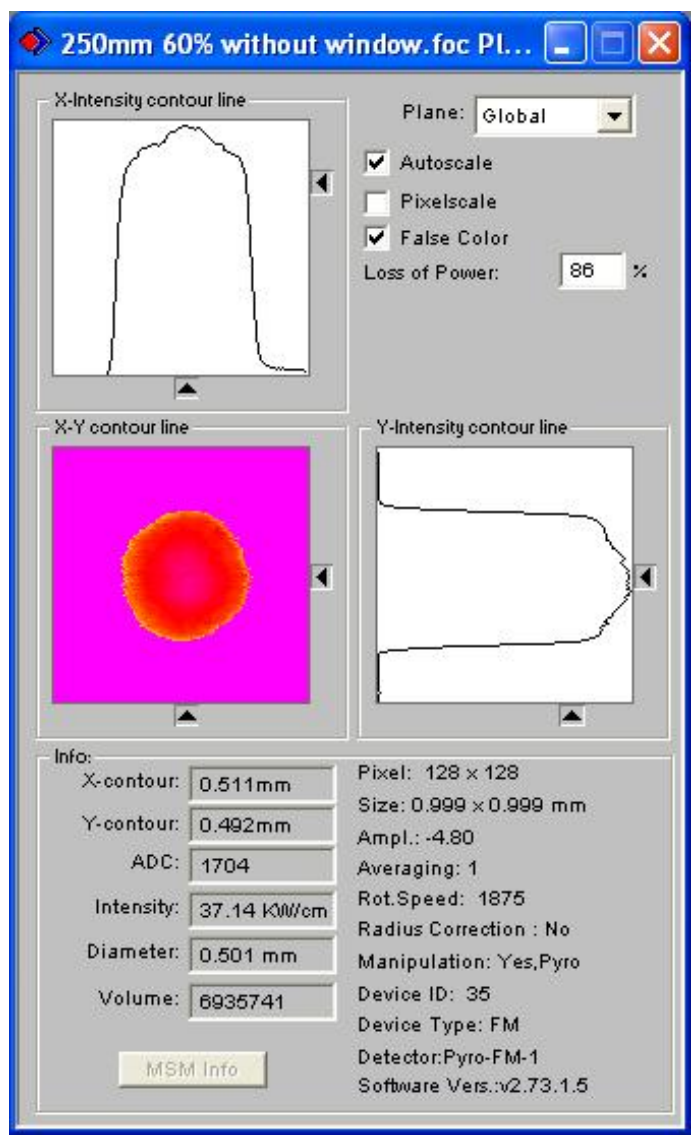

Figure A.2 - Single Measurement of Main Welding Beam from Conventional Optics 


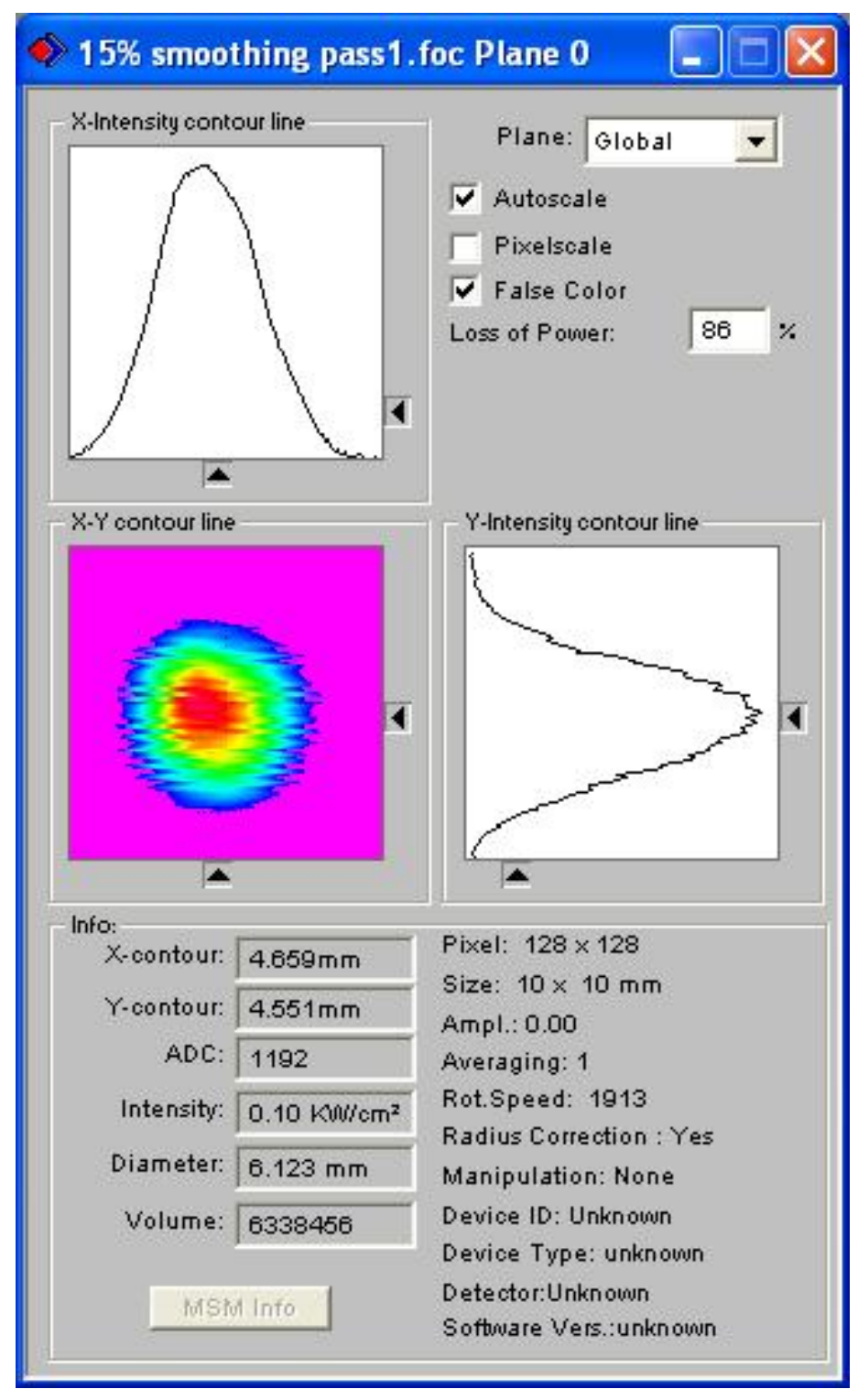

Figure A.3 - Measurement 1 of Out-of-Focus Smoothing Beam from Conventional Optics 


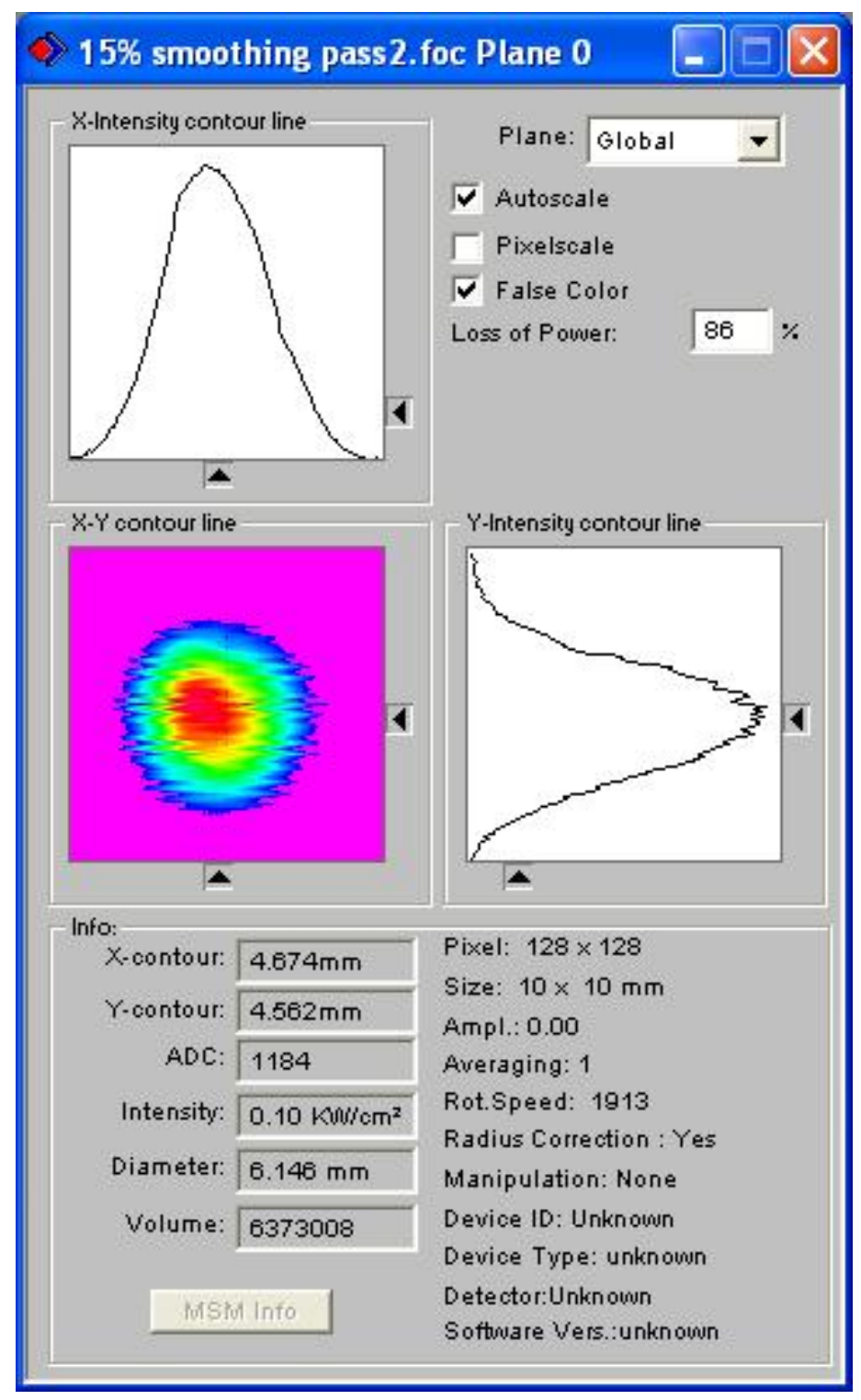

Figure A.4 - Measurement 2 of Out-of-Focus Smoothing Beam from Conventional Optics 


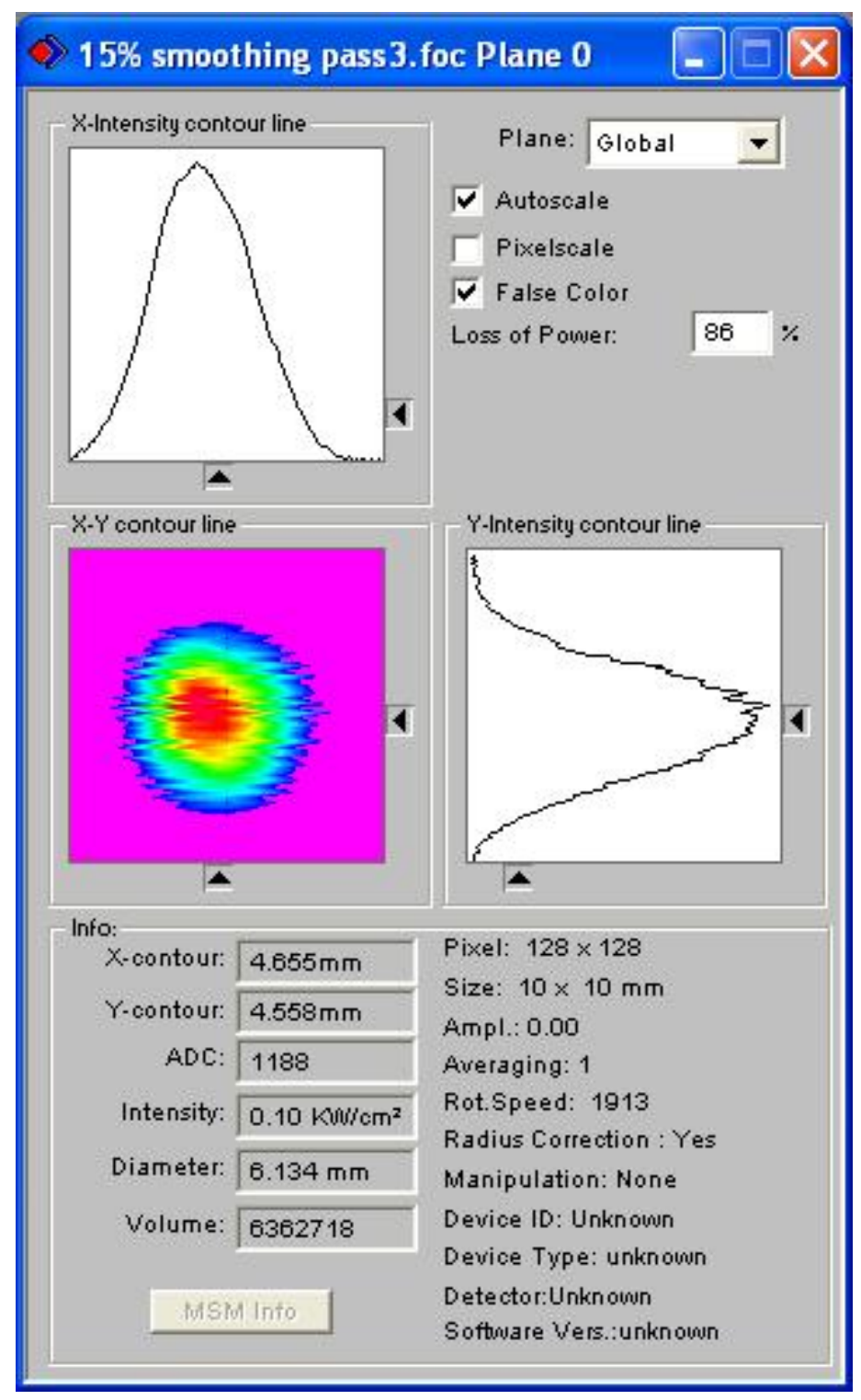

Figure A.5 - Measurement 3 of Out-of-Focus Smoothing Beam from Conventional Optics 
APPENDIX B

LASER POWER MEASUREMENTS 


\begin{tabular}{|c|c|c|c|}
\hline $\begin{array}{c}\text { Laser Set Point } \\
\text { (\% Current) }\end{array}$ & $\begin{array}{c}\text { Measured Power with } \\
\text { Conventional Optics } \\
(\mathrm{W})\end{array}$ & $\begin{array}{c}\text { Measured Power } \\
\text { with Custom Optics } \\
(\mathrm{W})\end{array}$ & $\begin{array}{c}\text { Calculated } \\
\text { Power } \\
\text { Loss } \\
(\%)\end{array}$ \\
\hline 10 & 505 & 494 & 2.2 \\
\hline 20 & 1552 & 1520 & 2.1 \\
\hline 30 & 2607 & 2548 & 2.3 \\
\hline 40 & 3652 & 3580 & 2.0 \\
\hline 50 & 4713 & 4608 & 2.2 \\
\hline 60 & 5744 & 5634 & 1.9 \\
\hline 70 & 6789 & 6659 & 1.9 \\
\hline 80 & 7830 & 7670 & 2.0 \\
\hline 90 & 8898 & 8708 & 2.1 \\
\hline 100 & 9910 & 9705 & 2.1 \\
\hline \multicolumn{3}{|c|}{ Average Power Loss } & 2.1 \\
\hline
\end{tabular}

Table B.1 - Power Measurements of Conventional Optics and Custom Optics 